\title{
Deformation Mechanisms in NiTi-Al Composites Fabricated by Ultrasonic Additive Manufacturing
}

\author{
Xiang Chen ${ }^{1} \cdot$ Adam Hehr $^{2} \cdot$ Marcelo J. Dapino ${ }^{2} \cdot$ Peter M. Anderson ${ }^{1}$
}

Published online: 8 September 2015

(C) ASM International 2015

\begin{abstract}
Thermally active NiTi shape memory alloy (SMA) fibers can be used to tune or tailor the effective coefficient of thermal expansion (CTE) of a metallic matrix composite. In this paper, a novel NiTi-Al composite is fabricated using ultrasonic additive manufacturing (UAM). A combined experimental-simulation approach is used to develop and validate a microstructurally based finite element model of the composite. The simulations are able to closely reproduce the macroscopic strain versus temperature cyclic response, including initial transient effects in the first cycle. They also show that the composite CTE is minimized if the austenite texture in the SMA wires is $\langle 001\rangle_{\mathrm{B} 2}$, that a fiber aspect ratio $>10$ maximizes fiber efficiency, and that the UAM process may reduce hysteresis in embedded SMA wires.
\end{abstract}

Keywords SMA - Composite material - Coefficient of thermal expansion · Finite element analysis · Ultrasonic additive manufacturing . Thermomechanical behavior

This article is an invited paper selected from presentations at the International Conference on Shape Memory and Superelastic Technologies 2014, held May 12-16, 2014, in Pacific Grove, California, and has been expanded from the original presentation.

Xiang Chen

chen.2303@osu.edu

1 Department of Materials Science and Engineering, The Ohio State University, 2041 College Rd., Columbus, OH 43210, USA

2 Department of Mechanical and Aerospace Engineering, The Ohio State University, 201 W. 19th Avenue, Columbus, OH 43210, USA

\section{Introduction}

Metal matrix composites (MMCs) with shape memory alloy (SMA) reinforcements have attracted increased attention [1, 2] due to an increased demand for lightweight smart materials in the automotive, biomedical, and aerospace industries [3, 4]. Aluminum matrix composites containing aligned NiTi SMA wires are candidates for light-weight, low thermal expansion applications. In principle, these composites can be tuned to have specified thermal expansion characteristics by controlling the NiTi volume fraction, processing, and interaction between phases.

Initially, NiTi shape memory composites with polymer matrices received greater attention initially because they are relatively simple to fabricate $[5,6]$. However, the low thermal conductivity and poor compatibility of the matrix with NiTi wires greatly limits the composite response and effectiveness of the NiTi wires. NiTi composites with metal matrices address the above problems but they are difficult to fabricate with traditional methods. These traditional methods prohibit joining of the NiTi in the pre-stressed martensitic phase and require post process cold working to utilize the shape memory effect [7-9]. Also, they require elevated temperatures that can cause melting and formation of brittle intermetallic phases, thus degrading the shape memory characteristics of NiTi.

Ultrasonic additive manufacturing (UAM) is a lowtemperature, solid-state welding process that can be used to make functional NiTi metal matrix composites [10-12]. UAM combines ultrasonic metal welding, mechanized foil layering, and $\mathrm{CNC}$ machining to fabricate gapless, 3D metal parts with intricate internal channels or embedded materials [13] such as NiTi fibers. The physics of the ultrasonic metal welding process produces metallic bonding at temperatures below the melting temperature [14]. In 


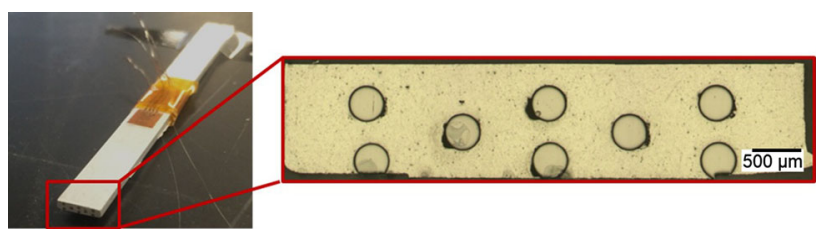

Fig. 1 A NiTi-Al composite (macroview-left; cross-sectonal viewright) fabricated by ultrasonic additive manufacturing (UAM)

particular, metallic bonds in UAM are formed by scrubbing the constituent metals together at high frequency $(\sim 20 \mathrm{kHz})$ under pressure. This plastically deforms surface asperities and exposes nascent metal for bonding. Dynamically recrystallized regions have been observed at depths $\sim 10 \mu \mathrm{m}$ from the surface $[15,16]$. Thus, NiTi fibers can be seamlessly integrated into metallic structures, including pre-stressed martensite. Figure 1 shows a NiTi$\mathrm{Al}$ composite that was fabricated using UAM; it displays a reduced and tunable CTE.

Prior to the UAM process, the NiTi fibers in a NiTi-Al composite were pre-stressed at room temperature in a martensitic (low temperature) state, and then unloaded. This process stretches the fiber inelastically and reorients the martensite $(\mathrm{M})$, thereby enabling the fiber to contract upon subsequent heating. Following the UAM joining process, both the fiber and the matrix are assumed to be stress-free initially. When heated above the martensite-toaustenite $(\mathrm{M} \rightarrow \mathrm{A})$ transition temperature, the fibers transform to the high-temperature austenite (A) phase, thereby contracting the fiber inelastically. This axial contraction (i.e., actuation) opposes the continued expansion of the matrix and thereby reduces the composite CTE. This strategy provides a light, stiff, and thermally stable material for engineering applications [17].

A distinguishing feature of the present work is that SMA reinforcements are inserted into MMCs in the martensitic state-made possible by UAM. In constrast, other SMAreinforced MMCs in the literature [1, 18, 19] involve embedding techniques at or above the recrystallization temperatures of the components. These embedding techniques are therefore above the $A_{f}$ temperature of SMAs and therefore do not permit the control of oriented martensite that is possible in the present work. A corresponding outcome is that few of the many modeling frameworks for the stress-temperature coupled response of SMA-reinforced composites [20-24] are applicable to capture the preprocessing of NiTi fibers as to reorient martensite, prior to insertion into the matrix.

Figure 2 provides a qualitative description of the stresstemperature $(\sigma-T)$ response within the embedded fiber during heating/cooling of the composite. The lower and upper bands denote regions in which the respective $\mathrm{M} \rightarrow \mathrm{A}$ and $\mathrm{A} \rightarrow \mathrm{M}$ transformations are possible. Initially, the wires
Fiber state evolution in NiTi phase diagram

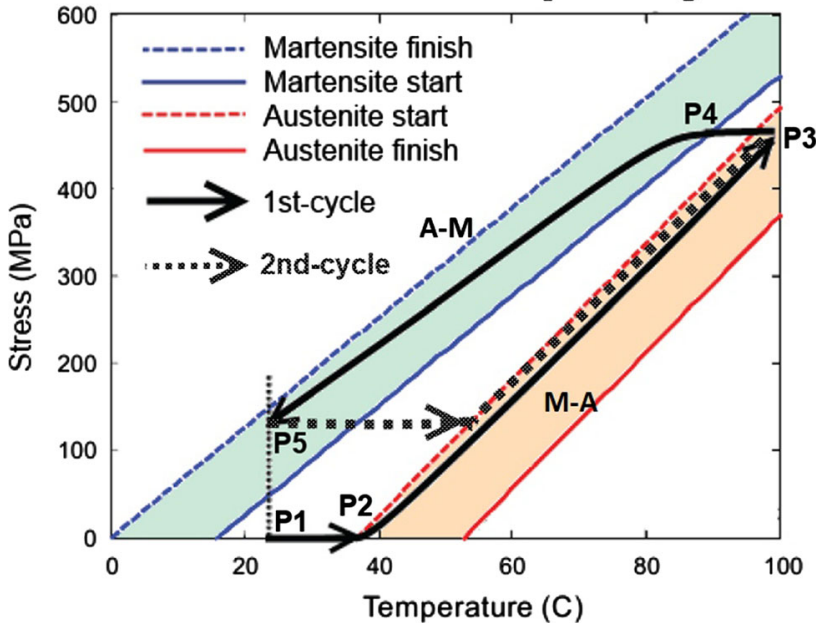

Fig. 2 Schematic stress-temperature path (P1, .. P5) of an embedded NiTi fiber during thermal cycle of the composite, shown on a stress-temperature phase diagram

are assumed to be stress-free (point P1). When the composite is heated to point $\mathrm{P} 2$, a relatively small stress may develop due to the CTE mismatch between the fiber and matrix. At point $\mathrm{P} 2$, the $\mathrm{M}-\mathrm{A}$ transformation commences, thereby inducing inelastic contraction of the wires. This creates a tensile axial stress in the NiTi fibers that increases during heating to the maximum temperature (point P3). Upon initial cooling, the A phase is stable to point P4 below which the $\mathrm{A} \rightarrow \mathrm{M}$ transformation commences. At the end of the thermal cycle (point P5), the fiber is expected to have a residual tensile stress and a different mixture of A and $\mathrm{M}$ than at point $\mathrm{P} 1$. Thus, subsequent cycles are expected to follow a different $\sigma-T$ path.

Theoretically, the actuation performance of the shape memory wires can be evaluated by the actuation stress in the wire when mechanically constrained, or by the actuation strain in the absence of an applied stress [25]. However, these ideal conditions do not apply to the embedded NiTi fibers. In principle, simulations should incorporate fiber texture, the thermodynamics of the forward and reverse phase transformation, matrix plasticity, thermal expansion, and compatibility between the matrix and fibers. Figure 2 is simplistic because the fiber stress state is multiaxial and inhomogeneous. Also, the UAM process may produce voids in the matrix around embedded $\mathrm{NiTi}$ fibers; these can persist or collapse if the matrix plastically deforms during thermal cycling. Thus, numerous factors can affect composite performance [26].

The primary goals of this paper are three-fold. The first is to experimentally characterize the thermal cycling behavior of NiTi-Al composites. Next a microstructurally based finite element model is developed to accurately predict this behavior. Finally, the model is used to investigate the effect 
of NiTi fiber parameters, including crystallographic orientation and aspect ratio, on the composite behavior.

\section{Experimental Characterization and Composite Fabrication}

\section{Material Characterization}

Mechanically polished, $0.381 \mathrm{~mm}$ (0.015 in.) diameter NiTi fibers were purchased from Nitinol Devices and Components, Inc. The fibers had an austenite start temperature $\left(A_{\mathrm{s}}\right)$ above room temperature and were trained to be straight in the undeformed austenitic state. Prior to composite fabrication, $158.8 \mathrm{~mm}$ (6.25 in.) long NiTi fibers were mechanically stabilized [27] by applying ten tensile loading-unloading cycles at $75^{\circ} \mathrm{C}$, which is above the austenite finish temperature $\left(A_{\mathrm{f}}\right)$. An extension rate of $1.27 \mathrm{~mm} / \mathrm{min}$. (engineering strain rate $=1.33 \times 10^{-4} / \mathrm{s}$ ) was imposed to a peak stress of $580 \mathrm{MPa}$, using a TestResources 131R1000-6 tensile frame with a thermal chamber and MTS Screw-Action Grips with serrated faces. The resulting fibers exhibited a stable, closed-loop, and stress-strain response by the 10th cycle.

The stabilized NiTi fibers were characterized using isothermal tensile testing and differential scanning calorimetry (DSC). Single-cycle isothermal tensile tests were performed on the NiTi fibers at 65,75 , and $85{ }^{\circ} \mathrm{C}$ to quantify cycle-to-cycle changes in stress-strain response as a function of temperature. An extension rate of $1.27 \mathrm{~mm} / \mathrm{min}(0.05 \mathrm{in} . /$ min) was chosen to minimize internal heating during the test [28]. The nominal strain was computed by dividing the measured axial extension of the fiber by the original length (158.8 mm).

The transformation temperatures were measured using a TA Instruments 2920 Differential Scanning Calorimeter. The sample was first cooled to approximately $-10{ }^{\circ} \mathrm{C}$ (i.e., far below the martensite finish temperature $M_{\mathrm{f}}$ ) to transform the fiber to a fully martensitic state. It was then heated to 100 at $10{ }^{\circ} \mathrm{C} / \mathrm{min}$ while simultaneously measuring the reference heat flow. The transformation temperatures were obtained by fitting lines to both sides of the transformation peak, and then determining the intersections between the plateaus [29]. This DSC system was not used to measure the martensitic transformation temperatures because reliable results for cooling could not always be achieved.

\section{Composite Design, Fabrication, and Testing}

A $9 \mathrm{~kW}$ UAM system (Fig. 3) was used to fabricate composites with aligned SMA fibers in an Al 6061-H18 matrix (obtained by work-hardening annealed Al 6061). The matrix was consolidated from $0.152 \mathrm{~mm}$ (0.006 in.) thick by $25.4 \mathrm{~mm}$ ( 1 in.) wide foils. Al 6061 was chosen to achieve a high strength-to-weight ratio and because it has good compatibility with UAM.

Figure 4a shows that adjacent fibers were staggered to that the fibers do not share the same interface boundaries between the UAM Al layers. The purpose is to minimize delamination along the interface boundaries. Fiber placement and encapsulation were assisted by cutting a channel $\sim 0.356 \mathrm{~mm}$ (0.014 in.) deep into the Al matrix using a $0.397 \mathrm{~mm}$ (0.016 in.) diameter ball-nose end mill. The channel dimension was $\sim 0.025 \mathrm{~mm}$ (0.001 in.) smaller than the NiTi fiber diameter to promote scrubbing for oxide removal and plastic flow of the Al matrix around the fiber (Fig. 4b). The dimensions of the Al 6061-T6 build plates used for composite fabrication were $101.6 \mathrm{~mm} \times 76.2 \mathrm{~mm}$ (4.0 in. by 3.0 in.) and $4.76 \mathrm{~mm}(0.188$ in.) thick. The plates were fixed using a custom fabrication fixture and vacuum chuck. The aluminum tapes were welded using a $6000 \mathrm{~N}$ down force and $34.6 \mu \mathrm{m}$ actuation amplitude, at a rate of $84.6 \mathrm{~mm} / \mathrm{s}$ (200 in./min). All welding was performed at room temperature $\left(22^{\circ} \mathrm{C}\right)$ rather than elevated temperature to avoid sample overheating during fabrication. These welding parameters, which were adopted from a recent design-of-experiments study to optimize the welding parameters of Al 6061-H18 [30], been shown to be sufficient in pilot NiTi-Al welds. The fibers were prestressed up to $580 \mathrm{MPa}$, unloaded as described earlier, and then placed in the channels for UAM welding.
Fig. 3 State-of-the-art UAM system fitted with a $9 \mathrm{~kW}$ weld head (inset), a 3-axis CNC mill with a 25 HP (8000 RPM) spindle, and an integrated $40 \mathrm{~W}$ laser.
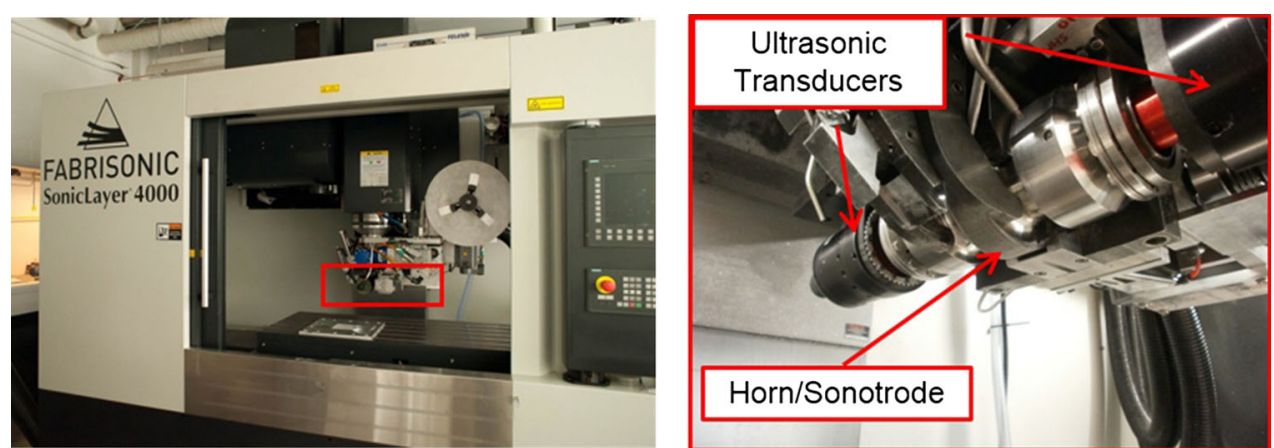


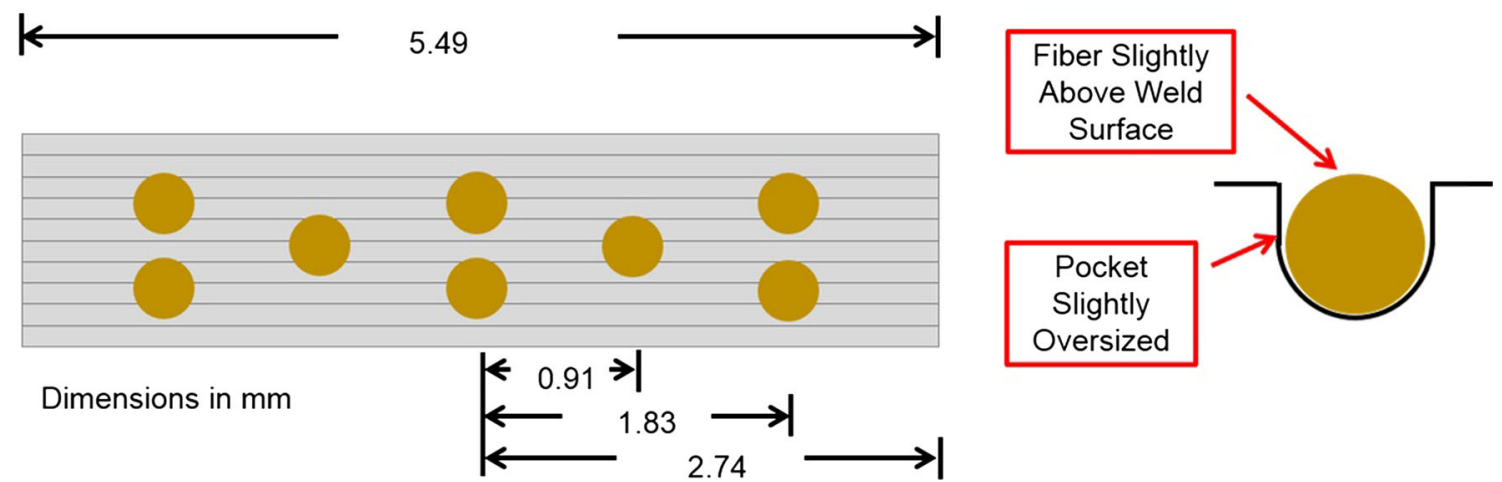

Fig. 4 Composite design: a fiber placement to eliminate shared interface boundaries between adjacent fibers and minimize delamination; b pocket design for fiber placement

Fig. 5 Thermal test to measure the composite coefficient of thermal expansion (CTE)
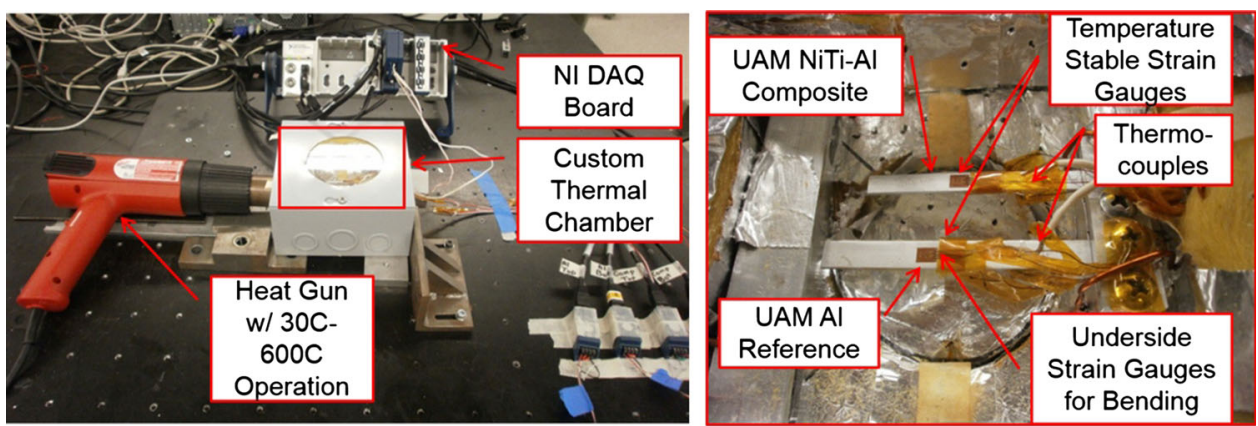

Multiple steps were used to remove the completed composite from the build plate surface: (i) $\mathrm{CNC}$ milling to reduce the composite geometry to final dimensions; (ii) manual milling to remove the build plate from under the composite; and (iii) slow speed cutting with a wheel to remove the end of the composite from the remaining build plate, with highvolume coolant to minimize heating. Two composites with dimensions $\sim 5.49 \mathrm{~mm} \times 74.00 \mathrm{~mm} \times 1.27 \mathrm{~mm} \quad(0.22$ in. $\times 2.91$ in. $\times 0.05$ in.) were fabricated. The resulting NiTi volume fractions for the two composites were different (13 vs. $13.8 \%$ ) due to variations in the removal process.

The composite CTE values were measured relative to a pure UAM Al 6061 matrix reference sample using a custom thermal chamber with foil-faced fiberglass insulation and a viewing hole (Fig. 5). A Milwaukee Variable Temperature Heat Gun and an aluminum baffle were used to uniformly distribute heated air to the chamber. Two samples-a composite and a pure UAM matrix reference-were mounted within the chamber in a stress-free, cantilevered condition. Strain gages (Micro Measurement WK 13031CF350) were mounted to the top and bottom sides of both samples, approximately $3.8 \mathrm{~cm}(1.5 \mathrm{in}$.) from the fixed end. The temperature of each sample was measured using Type $\mathbf{J}$ thermocouples with Omegatherm 201 thermal conductivity paste at the composite-thermocouple interface. The strain gage and thermocouple outputs were recorded with a
National Instruments data acquisition system interfaced with a LabVIEW VI. Prior to each test, the strains were zeroed using the calibration features within LabVIEW. The samples were heated from room temperature to approximately $100{ }^{\circ} \mathrm{C}$ over a $45 \mathrm{~min}$ period. They were then cooled by setting the heat gun air temperature to $30{ }^{\circ} \mathrm{C}$. This continued until the heat gun could no longer cool the sample. The sample was then cooled to room temperature by natural convection over an hour-long period [31].

Figure 6 shows optical microscope images before and after thermal cycling, acquired with an Olympus GX71 microscope using standard polishing procedures [32]. No cracks were observed before and after testing, suggesting that the build procedure can be scaled to larger structures and does not fracture during thermal cycling. Figure $6 \mathrm{a}$ shows voids around fibers after initial construction. They are hypothesized to arise from insufficient fiber surface roughness [33]. Figure $6 \mathrm{~b}$ shows reduced porosity after thermal cycling. Foster et al. [34] reports finer scale porosity in the aluminum phase, along the numerous interfaces created by the UAM process. This porosity is not readily observed in more macroscale images (Fig. 6) and is modeled as relatively insignificant compared to the macroscopic porosity. Based on the limited number of cross-sectional images, the pore volume fraction is estimated to be $5 \%$, prior to any thermal cycling. 


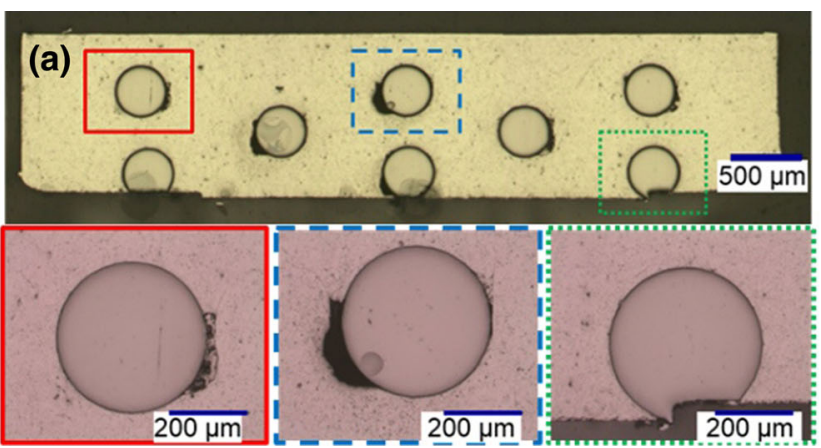

Fig. 6 Optical cross-section images showing consolidation quality of the 13.8 vol\% composite: a before testing (taken at composite end). Voids can be seen around various fibers yet no cracks are observed

The elevated temperature constitutive response of the $\mathrm{Al}$ matrix was measured using a TestResources 131R1000-6 load frame and Micro Measurement WK 13031CF350 strain gages. Tensile tests were carried out on a UAM Al 6061 sample without fibers, after machining to a flat ASTM E8 [35] sub-size specimen. A $100{ }^{\circ} \mathrm{C}$ maximum test temperature was chosen to correspond to the maximum temperature for subsequent CTE measurements. The imposed deformation rate was $0.127 \mathrm{~mm} / \mathrm{min}$. (engineering strain rate $=6.7 \times 10^{-5} / \mathrm{s}$ ), consistent with ASTM E21 [36]. This rate was maintained up to sample failure.

\section{Numerical Simulation of Composite Response}

Previous models of the UAM-fabricated NiTi-Al composite utilized a phenomenological approach implemented in MATLAB [17]. Although they require little computational power, the phenomenological nature of these models prevents the numerical investigation into the insight on the underlying mechanisms responsible for the composite behavior. In this work, a microstructural finite element model is adopted to capture physical mechanisms such as NiTi texture, martensite variant interaction, and matrix plasticity. Overall, it can simulate a variety of engineering materials and predict the stress redistribution and local thermo-elastic response within the composite. The NiTi constitutive model [37] is implemented as a User-defined MATerial (UMAT) subroutine in Abaqus [38]. The model is utilized to explore the above-mentioned physical mechanisms, their interactions, and ultimately their determination of the composite behavior.

\section{Simulation Geometry and Constitutive Relations}

Figure 7 shows a FE model geometry as implemented in Abaqus [38]. A representative volume element is identified as a single NiTi fiber plus the surrounding matrix that is

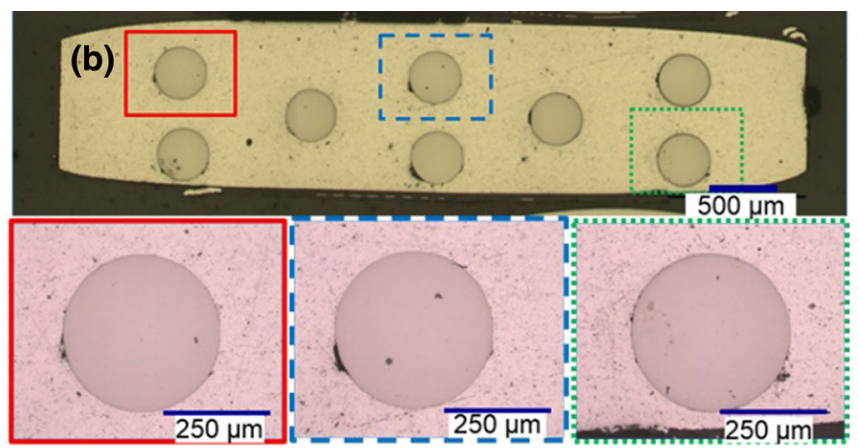

and interfaces between weld layers are not visible; b after three thermal cycles (taken at the strain gage location, Fig. 5) showing that the composite remained crack-free and that porosity is reduced

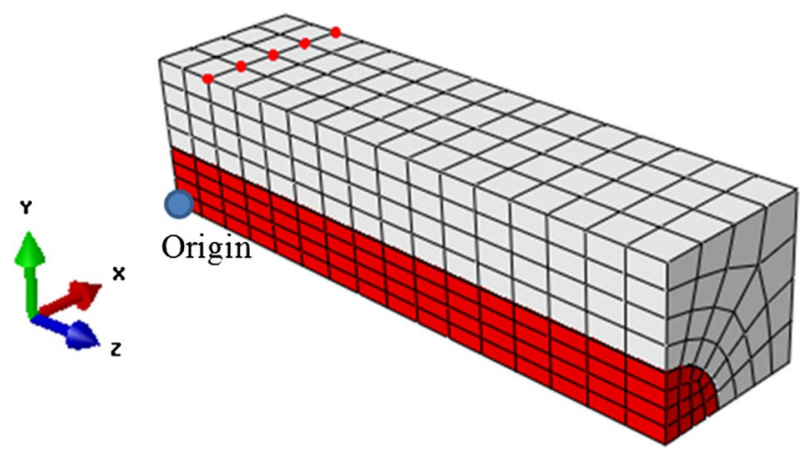

Fig. 7 Finite element model for the composite showing the NiTi SMA fiber and surrounding Al matrix. Surfaces passing through the "Origin" node are mirror planes

associated with a single fiber, assuming $13 \%$ volume fraction of fibers. One-eighth of this Representative Volume Element (RVE) was modeled as shown in Fig. 7. Mirror conditions were imposed on the $x y$-, $y z$-, and $x z$-planes that pass through the Origin point and the remaining surfaces were traction-free. This is consistent with zero net average stress in the transverse directions to the fiber. The tractionfree boundary condition on the $y z$ surface away from the Origin permits the $y z$ surface to become nonplanar during heating and cooling as to capture fiber end effects. A fiber aspect ratio $\mathrm{AR}=10$ was employed for the bulk of the results but the effect of $\mathrm{AR}$ on composite response is explored in more detail in "Effect of Fiber Aspect Ratio" section. Both the fiber and the Al matrix were meshed with eight-node, coupled-temperature-displacement, and reducedintegration elements (C3D8RT) in the Abaqus element library. An element-type study [39] determined that this element provides the best combination of accuracy and numerical efficiency when implementing the microstructural SMA constitutive relation to follow.

During heating and cooling, the temperature change at all material points was controlled so that the temperature is always homogeneous. The heat conduction problem was 
therefore not solved; this is appropriate in the limit of quasi-static heating and cooling. Overall, the one-eighth model produces the same results as the full RVE model. This modeling approach is able to capture the complex stress states associated with fiber end effects and it readily utilizes a microstructural finite element framework that incorporates anisotropic elasticity as well as both phase transformations and plasticity. It is more efficient than either a full RVE simulation or an entire simulation of the multi-fiber domain shown in Fig. 6.

A microstructural SMA constitutive law by Manchiraju and Anderson [37] was used for the NiTi fiber. It incorporates anisotropic elastic deformation and also inelastic deformation generated by the anisotropic, crystallographic, forward and reverse transformation between austenite and 24 correspondence variant pairs (CVP, also referred to as habit plane variants, see e.g., [40]) of M, as originally formulated by Thamburaja and Anand [41]. The model can also incorporate crystal-based plastic deformation in the austenite phase. The thermodynamic driving force $f_{i}$ for transformation from A to the $i$ th CVP of M is expressed as:

$$
\begin{aligned}
f_{i}\left(\boldsymbol{\sigma}, T, v_{1}, v_{2}, \ldots, v_{24}\right)= & \underbrace{\mathbf{b}_{i} \cdot \boldsymbol{\sigma} \mathbf{m}_{i}}_{\text {mechanical }}+\underbrace{\frac{\lambda_{\mathrm{T}}}{\Theta_{\mathrm{T}}}\left(\Theta_{\mathrm{T}}-T\right)}_{\text {thermal }} \\
& -\underbrace{\sum_{j=1}^{24} H_{i j} v_{j}}_{\text {CVP interaction }},
\end{aligned}
$$

where the volume fraction $v_{i}$ of each CVP is bounded by $0 \leq v_{i} \leq 1$ and the sum of all $v_{i}$ cannot exceed 1. $\sigma$ is the Cauchy stress; $\mathbf{b}_{i}$ and $\mathbf{m}_{i}$ are the respective shear and habit plane normal vectors of the $i$ th martensite CVP; $\lambda_{\mathrm{T}}$ and $\Theta_{\mathrm{T}}$ are the latent heat of the transformation and equilibrium transformation, respectively; $H_{i j}$ is a transformation hardening matrix that describes the interaction between the $i$ th and $j$ th CVPs. The driving force $f_{i}$ must always satisfy

$-f_{\text {crit }} \leq f_{i} \leq f_{\text {crit }}$,

where $f_{\text {crit }}$ is the critical driving force for transformation. It is evident from Eq. (2) that $f_{i}$ must reach $f_{\text {crit }}$ for the forward $\mathrm{A} \rightarrow \mathrm{M}$ transformation and $-f_{\text {crit }}$ for the reverse $\mathrm{M} \rightarrow \mathrm{A}$ transformation.

This constitutive relation is similar to a crystal-based yield surface in plasticity where $H_{i j}$ describes the hardening (self and latent) between different CVPs and where the sum of the $\mathrm{A}$ and $\mathrm{M}$ volume fractions equals 1 . The constitutive relation predicts the bands of $\mathrm{A}$ and $\mathrm{M}$ in $\sigma-T$ space as depicted in Fig. 2, where the separation, width, position, and slope of the bands are controlled by $f_{\text {crit }}, H_{i j}, \Theta_{\mathrm{T}}$, and $\lambda_{\mathrm{T}}$, respectively. The band features also vary with the crystallographic direction of the fiber axis. The original formulation is provided by
Thamburaja and Anand [41] and the extension to plasticity is provided by Manchiraju and Anderson [37].

A fiber volume fraction of $13 \%$ was assumed in all simulations, similar to the experimental values of 13 and $13.8 \mathrm{vol} \%$. The fiber-matrix interface was modeled as perfectly bonded, so that no slipping occurred during thermal cycling. This is consistent with the absence of interfacial debonding in the experiments. In "Simulations Assuming No Matrix Plasticity and Pre-UAM Fiber Properties" section, results assuming thermo-elastic deformation of the Al 6061 matrix are shown. In "Simulations Assuming Matrix Plasticity and UAM Modification of Fibers" section, a thermo-elastic-plastic matrix is introduced to match the composite thermal cycling data.

The simulations attempted to replicate the actual fabrication and testing of the composite. Figure 8 (left portionfiber only) shows that prior to bonding the fiber to the matrix, oriented $\mathrm{M}$ was induced in the simulations by cooling the fiber from a $T>A_{\mathrm{f}}$ to room temperature (RT = $22{ }^{\circ} \mathrm{C}$ ) while maintaining an axial stress $\sigma_{\text {bias }}=500 \mathrm{MPa}$. This magnitude was chosen to ensure oriented $\mathrm{M}$ during cooling and it is similar in magnitude to that in the experiments $(580 \mathrm{MPa})$. The oriented $\mathrm{M}$ fiber was then unloaded at RT. No reverse transformation occurred since $\mathrm{RT}<A_{\mathrm{s}}$ (Fig. 9b). This numerical step serves the same purpose as the isothermal pre-stressing or stretching, and then unloading of the fibers at RT prior to composite fabrication. The fiber was then bonded to the $\mathrm{Al}$ matrix by applying a "TIE" constraint in Abaqus to the two contacting surfaces. This ensured no relative sliding or opening of the interface between the two phases.

Figure 8 shows the first two of four thermal cycles between $T_{\min }=22{ }^{\circ} \mathrm{C}$ and $T_{\max }=100{ }^{\circ} \mathrm{C}$. The axial

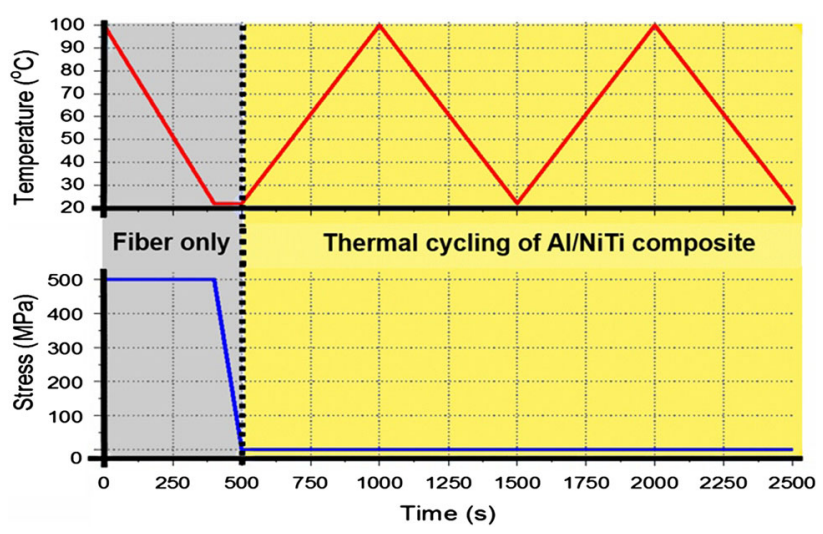

Fig. 8 Thermal-mechanical loading history in the FE simulations showing the (upper) temperature-time and (lower) stress-time history. During the first $500 \mathrm{~s}$, the fiber is stressed to $500 \mathrm{MPa}$, cooled, and then unloaded. At $t=500 \mathrm{~s}$, the fiber is bonded to the matrix as shown in Fig. 7. For $t>500 \mathrm{~s}$ (yellow region), the first two thermal cycles of composite are shown (Color figure online) 

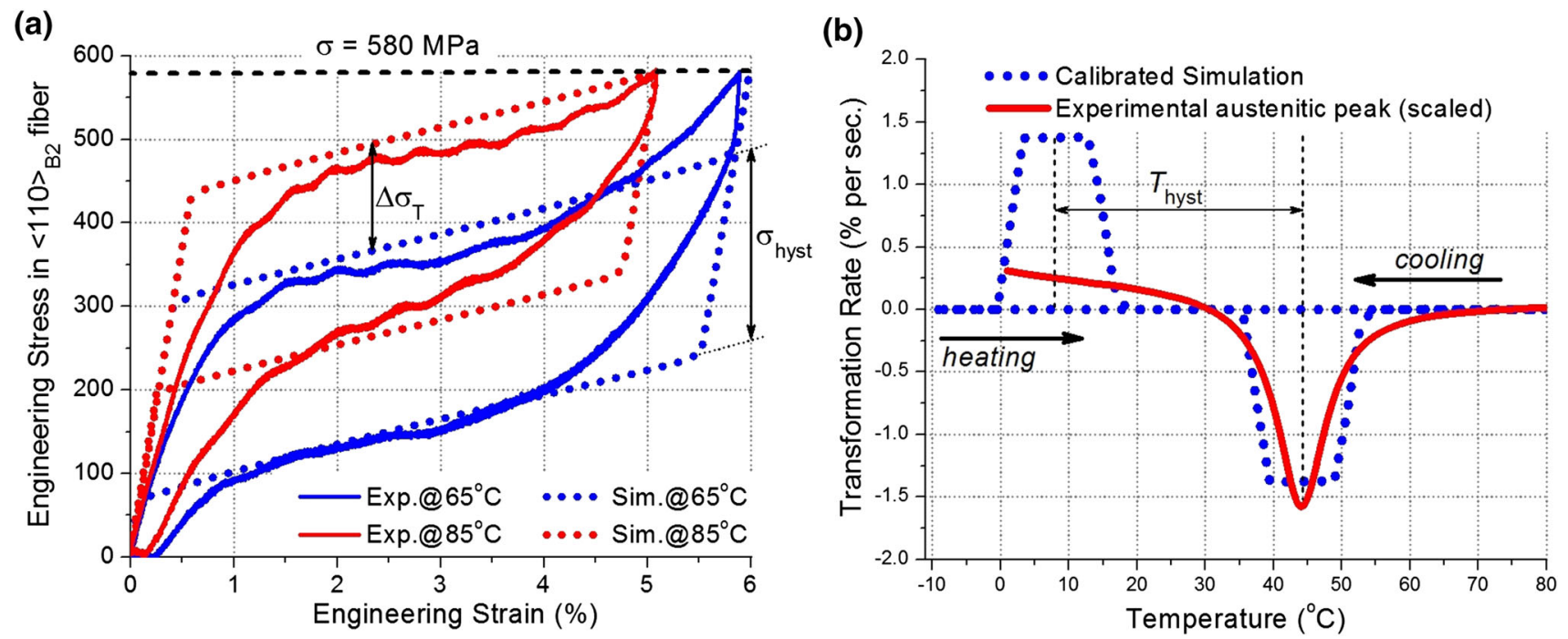

Fig. 9 NiTi FE model calibration showing the fit to experimental data: a uniaxial tension at 65 and $85{ }^{\circ} \mathrm{C}$ for a $\langle 110\rangle_{\mathrm{B} 2}$-oriented NiTi fiber; b DSC curves

composite strain was recorded at the outer surface of the matrix near the mirror plane perpendicular to the axis (Fig. 7, highlighted nodes). This location is far from any stress inhomogeneity induced by fiber end effects and it provides a measure of the average axial strain exhibited in the isostrain portion of the composite. Isostrain conditions are expected to dominate in the fabricated composites where fiber aspect ratios $>100$.

The simulation results are presented in three sections. "Calibration of NiTi SMA Properties Prior to UAM" section describes the calibration of model parameters for NiTi SMA fibers against two types of experimental results: (1) tensile stress-strain curves at three pseudoelastic temperatures; and (2) the DSC response for the reverse transformation. "Simulations Assuming No Matrix Plasticity and Pre-UAM Fiber Properties" section presents the composite simulation results based on two assumptions: (1) the embedded fibers have the same properties before and after the UAM joining process; and (2) the Al matrix undergoes only thermo-elastic (non-plastic) deformation. "Simulations Assuming Matrix Plasticity and UAM Modification of Fibers" section relaxes these two assumptions in an effort to improve the agreement between experiments and simulation results.

\section{Calibration of NiTi SMA Properties Prior to UAM}

The model parameters for the fiber are calibrated to two sets of experimental results before fiber embedding: (1) isothermal uniaxial tension stress-strain curves at 65, 75 (not shown), and $85^{\circ} \mathrm{C}$ (Fig. 9a); and (2) reverse transformation DSC peaks (Fig. 9b). These values are summarized in Table 1. In particular, the value of $f_{\text {crit }}$ is calibrated to the vertical hysteresis $\sigma_{\text {hyst }}$ in Fig. 9a. The value of $\Theta_{\mathrm{T}}$ was then calibrated to match the temperature $T_{\text {peak }}\left(44{ }^{\circ} \mathrm{C}\right)$ in the DSC data (Fig. 9b). The value of $\lambda_{\mathrm{T}}$ was then calibrated to match the shift $\Delta \sigma_{\mathrm{T}}$ associated with a change in test temperature. Finally, the hardening matrix $\mathbf{H}$ was calibrated to the slope $S$ of the $\sigma-\varepsilon$ response. The transformation strain $\gamma_{0}$ is adopted from the Crystallographic Theory of Martensite (CTM), as discussed in Manchiraju and Anderson [37]. That work describes the systematic method of calibration adopted here. It also provides a value of $\gamma_{0}$ based on CTM that is applicable for the cubic-to-monoclinic phase transformation in this NiTi alloy.

In general, the local "neighborhood" texture can alter the response of individual grains within polycrystals [42]. In this case, NiTi fibers were purchased from the same source (Nitinol Devices \& Components, Inc.) as used by Kim and Daly [43]. That work reports a $\langle 110\rangle_{\mathrm{B} 2}$ crystallographic texture along the fiber axis based on RD inverse pole data provided in Fig. 6 of their work. This work adopts a precise $\langle 110\rangle_{\mathrm{B} 2}$ orientation principally to allow independent, unambiguous confirmation of our results. This differs from the previous work of Hehr et al. [26] which assumed a $10^{\circ}$ random variation about a $\langle 110\rangle_{\mathrm{B} 2}$ fiber axis. This produces a $\sim 8 \%$ variation in the prediction of composite strain versus temperature results.

Table 2 summarizes the remaining constitutive parameters as adopted from the literature. These include the thermo-elastic constants of austenite and martensite obtained from first principles calculations and experiments, as summarized by Manchiraju and Anderson [37] and thermo-elastic constants for the Al matrix as summarized by Hahnlen and Dapino [11]. 
Table 1 NiTi phase transformation parameters determined by calibration to experiments

\begin{tabular}{ll}
\hline Parameter & Calibrated value \\
\hline Equilibrium transformation temperature & $\Theta_{\mathrm{T}}=310 \mathrm{~K}$ \\
Latent heat of transformation per unit vol. & $\lambda_{\mathrm{T}}=101 \mathrm{~J} / \mathrm{cm}^{3}$ \\
Transformation hardening matrix $\mathbf{H}$ & $H_{i j}=C_{44(\mathrm{~A})} / 2267(i=j) ;=C_{44(\mathrm{~A})} / 7933(i \neq j)$ \\
Critical driving force for transformation & $f_{\text {crit }}=5.7 \mathrm{~J} / \mathrm{cm}^{3}$ \\
Shear magnitude of transformation & $\gamma_{0} \equiv\left|\mathbf{b}_{i}\right|=0.1308$ for all CVPs \\
\hline
\end{tabular}

[31]
Table 2 Material constants adopted from the literature

\begin{tabular}{|c|c|}
\hline Parameter & Value \\
\hline Elastic constants of NiTi austenite (GPa) & $C_{11(\mathrm{~A})}=130, C_{12(\mathrm{~A})}=98, C_{44(\mathrm{~A})}=44$ \\
\hline Elastic constants of NiTi martensite ${ }^{\dagger}$ & Same as austenite \\
\hline NiTi coefficients of thermal expansion ${ }^{\dagger}$ & $\alpha_{(\mathrm{A})}=1.1 \times 10^{-5} \mathrm{~K}^{-1}, \alpha_{(\mathrm{M})}=6.6 \times 10^{-6} \mathrm{~K}^{-1}$ \\
\hline Elastic properties of $\mathrm{Al}^{*}$ & Young's modulus $E_{\mathrm{Al}}=68 \mathrm{GPa}$, Poisson's ratio $v_{\mathrm{Al}}=0.33$ \\
\hline $\mathrm{Al}$ coefficient of thermal expansion ${ }^{7 *}$ & $\alpha_{\mathrm{Al}}=2.36 \times 10^{-5} \mathrm{~K}^{-1}$ \\
\hline
\end{tabular}

* [11]

Figure 9a shows the simulated isothermal uniaxial tension stress-strain curves at 65 and $85{ }^{\circ} \mathrm{C}$, using the calibrated fitting parameters reported in Tables 1 and 2 . A maximum tension of $580 \mathrm{MPa}$ is imposed in all cases. The experimental curves are from so-called "stabilized" fibers and represent the response after ten cycles. In principle, such cycling can introduce additional defect accumulation and plastic strain [43]. However, stabilized fibers tend to have greater hardening and reduced incremental plastic ratcheting [26]. This is evident from the large slope along the transformation portion and the small amount of remnant plastic deformation at the end of the cycle. Accordingly, the present simulations assume that the fibers are fully stabilized and do not deform plastically. Figure $9 \mathrm{~b}$ compares the transformation rate versus temperature from the simulations and DSC experiments, along the reverse $(\mathrm{M} \rightarrow \mathrm{A})$ heating path.

The simulation results in Fig. 9a reproduced the transformation strain, hardening slope, Clausius-Clapeyron behavior, and hysteresis to within $10 \%$ of the experimental values. In Fig. 9b, the A peak temperature during heating agrees well with experiments. The simulation results also show the cooling $(A \rightarrow M)$ peak. Although a corresponding experimental cooling curve is not available, the simulations are consistent with observations that the fiber is fully austenitic at $22{ }^{\circ} \mathrm{C}$ and fully martensitic at $-10^{\circ} \mathrm{C}$.

\section{Simulations Assuming No Matrix Plasticity and Pre-UAM Fiber Properties}

Figure 10 shows the composite strain versus temperature $(\varepsilon-T)$ response for the first and the third cycles, for the experiments and simulations. Here, only thermo-elastic deformation (no plasticity) is assumed in the matrix and the fiber-matrix properties are the pre-UAM values defined in Tables 1 and 2 . The kink $(K)$ points in the simulation curves correspond to the onset of the $\mathrm{M} \rightarrow \mathrm{A}$ transformation in the fiber during heating and the $\mathrm{A} \rightarrow \mathrm{M}$ transformation during cooling. This is confirmed by noting the evolution of martensite volume fraction in Figs. 10c, d. The onset of transformation always triggers an abrupt change in the slope of the $\varepsilon-T$ curve, equivalent to an abrupt change in the composite coefficient of thermal expansion (CTE).

Figure 10a shows that the composite accumulates a negative axial strain during the first cycle. This is consistent with the qualitative trend proposed in Fig. 2. The simulation results in Fig. 10c reveal that the fiber began the cycle with 100 vol\% M but ended the cycle with only 93 vol\% M. The initial 100 vol\% M was induced during the simulated pre-stressing process, whereby the fiber was stressed to $500 \mathrm{MPa}$, cooled to RT, and then unloaded. During subsequent heating of the composite to $100{ }^{\circ} \mathrm{C}$, the fiber did not completely transform to A (Fig. 10c) because an axial tensile stress developed during the $\mathrm{M} \rightarrow \mathrm{A}$ transformation, thereby constraining further transformation. During cooling, the reverse $(\mathrm{A} \rightarrow \mathrm{M})$ transformation began at $57{ }^{\circ} \mathrm{C}$ but it did not complete because the magnitude of tension in the fiber was not sufficient.

The first cycle also altered the relative fractions of CVP types (Fig. 10e). Initially, the oriented martensite was composed of four CVPs-each with $25 \%$ volume fraction (blue-left bars in Fig. 10e). Upon cooling during the first cycle, the development of interfacial shear stress produced nonzero volume fractions of CVP5, CVP6, and CVP14. These were not present initially and are not favored by an axial tensile fiber stress. Both the altered CVP distribution and reduction in martensite volume fraction contribute to 

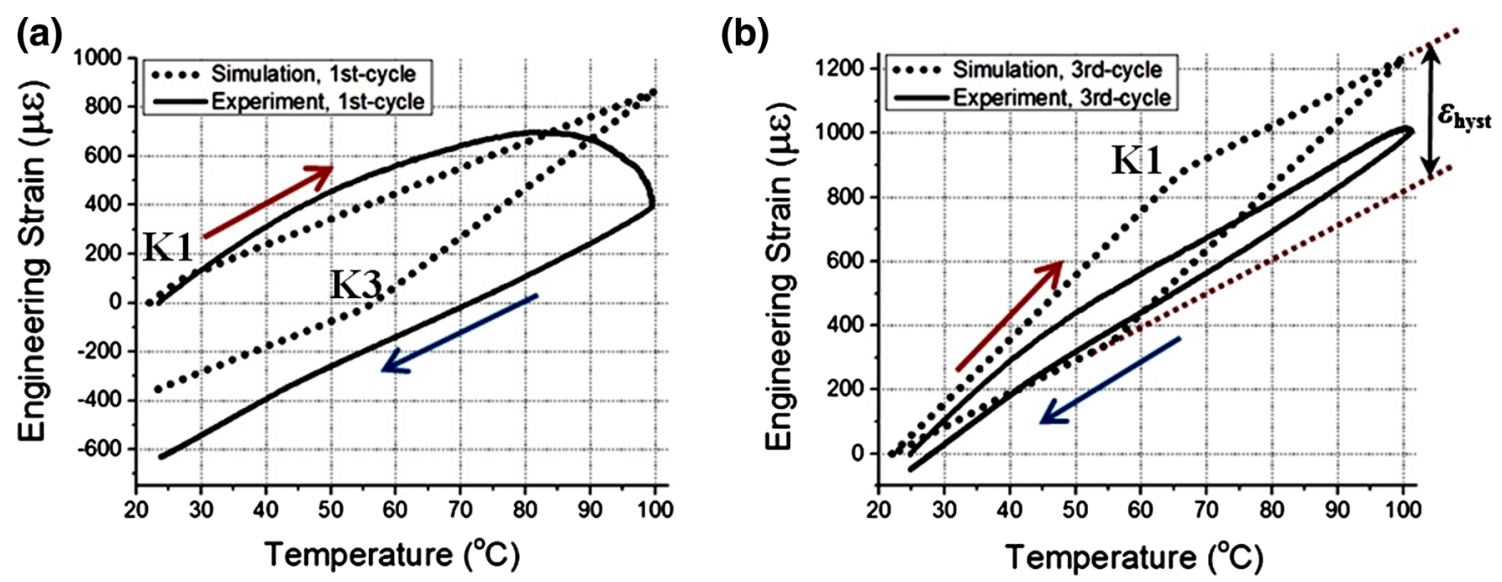

(c)

(d)
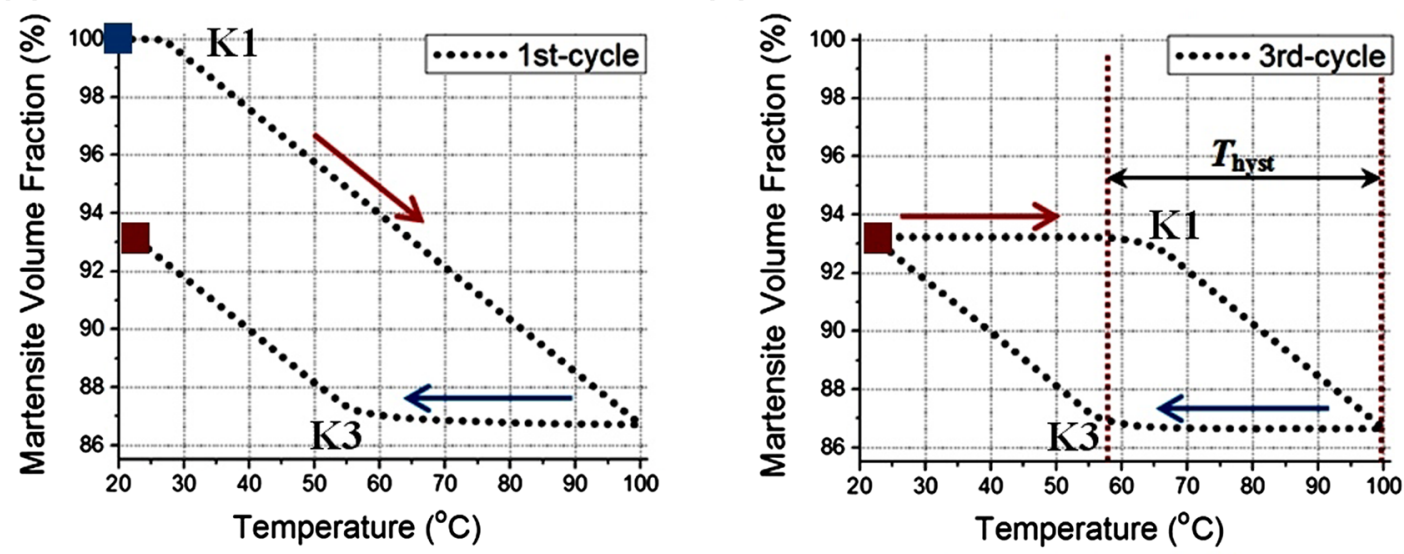

(e)

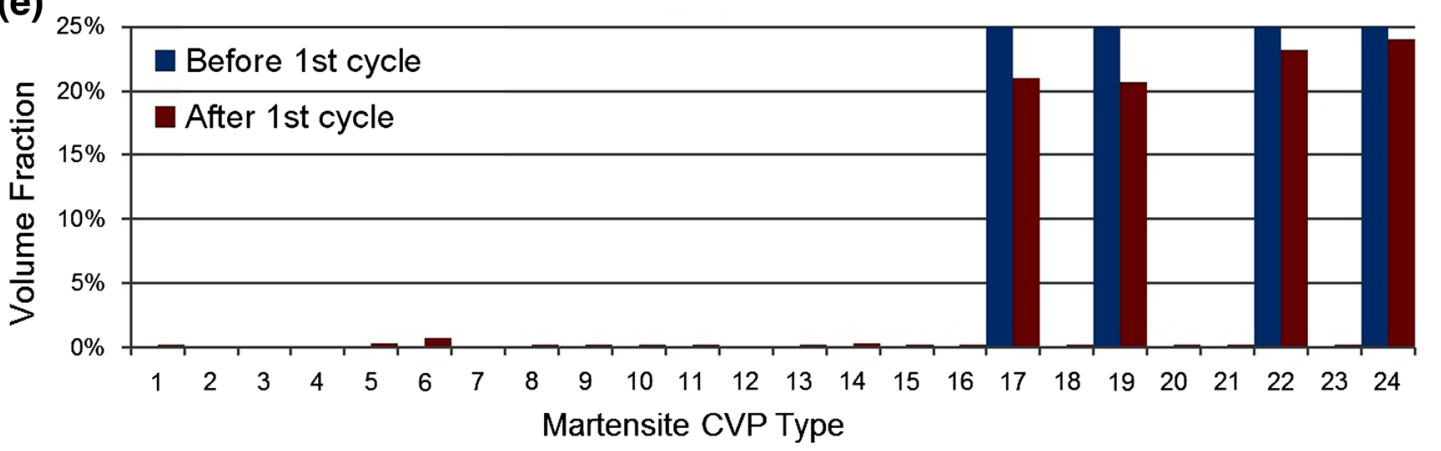

Fig. 10 Simulation results for a Al-NiTi composite with a thermoelastic (non-plastic) matrix and pre-UAM properties in Tables 1 and 2 , for a first cycle and $\mathbf{b}$ subsequent cycles (which overlap); $\mathbf{c}$ and d corresponding evolution of martensite volume fraction in the NiTi

the accumulated negative axial strain during the first cycle (Fig. 10a).

Figure $10 \mathrm{~b}$ shows the simulated $\varepsilon-T$ response for subsequent cycles 2 and beyond. Compared to cycle 1, the point $\mathrm{K} 1$ is displaced to the right by $\sim 35{ }^{\circ} \mathrm{C}$ and $\mathrm{K} 3$ is barely displaced. Table 3 shows that the simulated composite CTE below and above K1 agree well with the experimental data. However, the simulations over-predict fiber; e change of martensite CVP type during the first cycle-the left (blue) bar in each pair corresponds to the upper square (blue) point in (c) and the right (red) bar in each pair correspond to the lower square (red) point in (c) and square (red) point in (d) (Color figure online)

both the magnitude of strain hysteresis $\left(\varepsilon_{\text {hyst }}\right)$ and the CTE transition temperature (position of K1).

\section{Simulations Assuming Matrix Plasticity and UAM Modification of Fibers}

The simulations in "Simulations Assuming No Matrix Plasticity and Pre-UAM Fiber Properties" section are 
Table 3 Simulationexperiment comparison of CTE in heating for cycle 2 and beyond

\begin{tabular}{lll}
\hline & Before transformation (below K1) & During transformation (above K1) \\
\hline Experimental CTE $(\mu \varepsilon / \mathrm{K})$ & 23.6 & 11.10 \\
Simulated CTE $(\mu \varepsilon / \mathrm{K})$ & 23.6 & 10.48 \\
\hline
\end{tabular}

unable to explain or predict the curved $\varepsilon-T$ behavior during cycle 1 (Fig. 10a). They also under-predict the magnitude of accumulated compressive strain in cycles 1 and 3 (Figs. 10a, b) and over-predict the hysteresis and CTE transition temperature in cycle 3 . These deficiencies could not be addressed by varying the geometrical parameters, including the fiber aspect ratio and crystallographic orientation within the fiber. Accordingly, this section examines the modeling assumptions that (1) the matrix deforms only by elastic and thermal strain, and (2) the UAM process does not alter the shape memory properties of the NiTi fibers. The first assumption is suspect since the magnitudes of composite strain in Fig. 10a are sufficiently large to induce matrix plasticity. The second assumption is suspect since it has been well documented [44-46] that high-cycle loading of NiTi can significantly reduce the transformation hysteresis. During the UAM process, the ultrasonic head generates $\sim 50 \mathrm{MPa}$ nominal compression and oscillates by \pm 30 microns at a frequency of $20 \mathrm{kHz}$. Therefore, the UAM process imposes cyclically loads each material point in the composite with thousands of cycles, potentially reducing hysteresis in the NiTi fibers and dislocation motion and recrystallization of the $\mathrm{Al}$ matrix.

Figure 11 shows the uniaxial tensile response for postUAM Al-6061 without NiTi fibers, tested at both 20 and $100{ }^{\circ} \mathrm{C}$. The plastic segment of the $100{ }^{\circ} \mathrm{C}$ curve (from the proportional limit to ultimate stress) was imported into Abaqus in the form of yield stress versus equivalent plastic strain tabular data. This was viewed as a case with negligible porosity since the porosity associated with fibers was not present. The $100{ }^{\circ} \mathrm{C}$ response was used since this temperature was the upper limit to the subsequent thermal cycling on the composite. It is also most relevant since the largest plastic increments are expected to occur at this upper temperature limit. This is expected since the flow strength of the matrix reaches a minimum and the internal stress in the matrix reaches a maximum at the upper temperature. This is confirmed by the simulation results (Fig. 13b) that show a maximum in fiber stress at $100{ }^{\circ} \mathrm{C}$. The simulated response for $0 \%$ porosity closely captures the experimental response at $100{ }^{\circ} \mathrm{C}$.

As discussed in "Composite Design, Fabrication and Testing" section (Fig. 6), the UAM process introduces porosity in the form of pores near fibers as well as a ubiquitous, fine-scale porosity along aluminum interfaces, as discussed in Foster et al. [34]. Yield of porous matrices is pressure-dependent and not volume-conserving. To describe this phenomenon, a pressure-dependent continuum plasticity model proposed by Gurson [47] and generalized by Tvergaard [48] was employed. The Gurson-Tvergaard model is incorporated as Porous Metal Plasticity in the Abaqus material behavior library (Abaqus 6.12 Documentation, 2012). The yield condition for this model is.

$\left(\frac{s}{\sigma_{\mathrm{y}}\left(\bar{\varepsilon}^{\mathrm{pl}}\right)}\right)^{2}+2 q_{1} f \cosh \left(-q_{2} \frac{3 p}{2 \sigma_{\mathrm{y}}\left(\bar{\varepsilon}^{\mathrm{pl}}\right)}\right)-\left(1+q_{3} f^{2}\right)=0$,

where $s$ is the effective von Mises stress, $\bar{\varepsilon}^{\mathrm{pl}}$ is the equivalent plastic strain, $f$ is the void volume fraction (porosity), $p=-\operatorname{tr}(\sigma) / 3$ is the hydrostatic component of the Cauchy stress tensor $\sigma$, and $\sigma_{\mathrm{y}}\left(\bar{\varepsilon}^{\mathrm{pl}}\right)$ is the uniaxial yield strength of

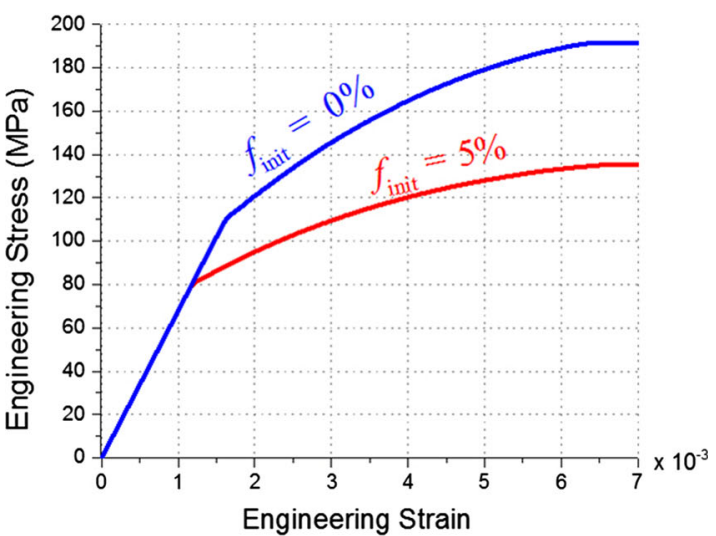

Fig. 11 a Experimental uniaxial stress-strain behavior of post-UAM Al 6061 at 20 and $100{ }^{\circ} \mathrm{C}$ and b simulations of the calibrated uniaxial stress-strain response at $100{ }^{\circ} \mathrm{C}$ for 0 and $5 \%$ initial porosity 


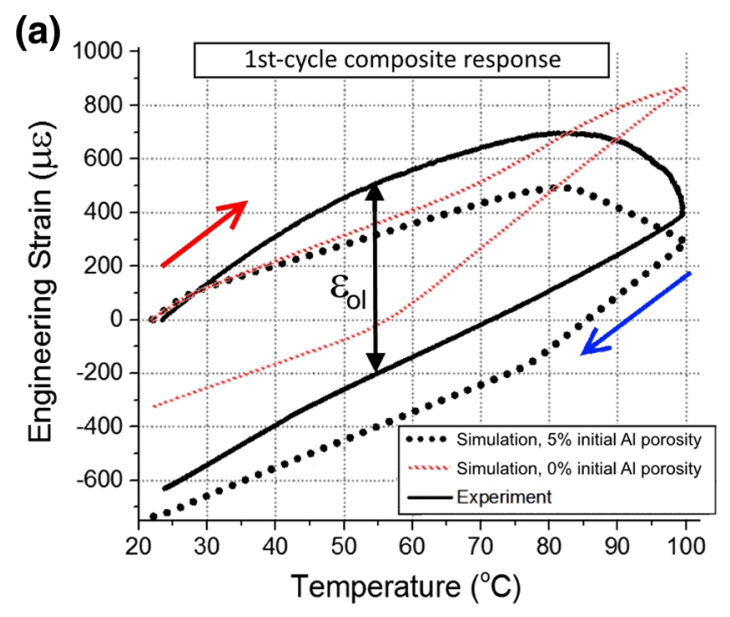

(c)

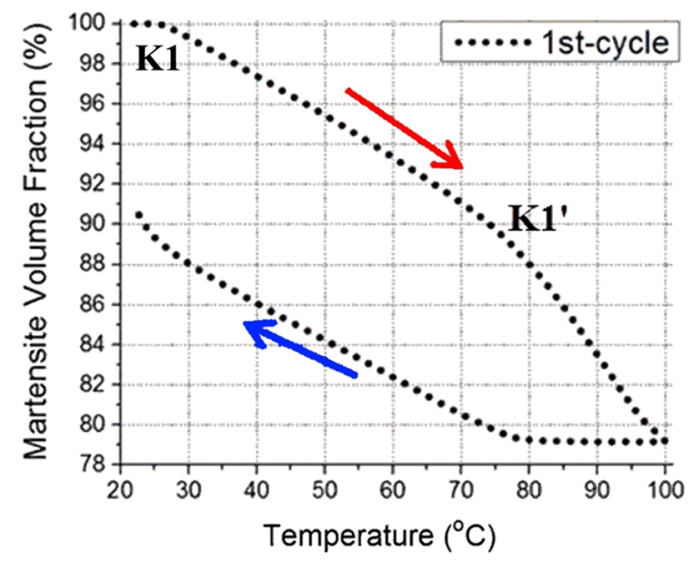

Fig. 12 Composite strain-temperature response showing experimental and simulated results for a first thermal cycle and $\mathbf{b}$ subsequent thermal cycles. The red dashed line in a shows the response assuming non-porous matrix plasticity and pre-UAM fcrit for fiber, while that in b uses a reduced $f_{\text {crit }}=2.85 \mathrm{~J} / \mathrm{cm}^{3}$ relative to the pre-UAM value. The final simulations (black dotted lines) use the reduced $f_{\text {cri }} \mathrm{t}$ value

the fully dense $(f=0)$ material, and its dependence on $\bar{\varepsilon}^{\mathrm{pl}}$ is given by the experimental curve in Fig. 11a as previously noted $q_{1}, q_{2}$, and $q_{3}$ are material parameters. The Gurson-Tvergaard model introduces a hydrostatic, pressure-dependent yield through the 2nd term in Eq. (3). Although this dependence usually is neglected in fully dense metals, it can be important in voided materials.

The Gurson-Tvergaard model is adopted throughout the matrix to capture the effect of the porosity observed in Fig. 6. In principle, these pores could be modeled discretely in the finite element framework. However, the three-dimensional, statistical nature of pore size and distribution is not available and would require numerous cross-sectional images or tomographic studies. Instead, we smear out the discrete pores by adopting a continuum description of porosity. In principle, the porosity is larger near fibers and decays with radial distance from fibers. This

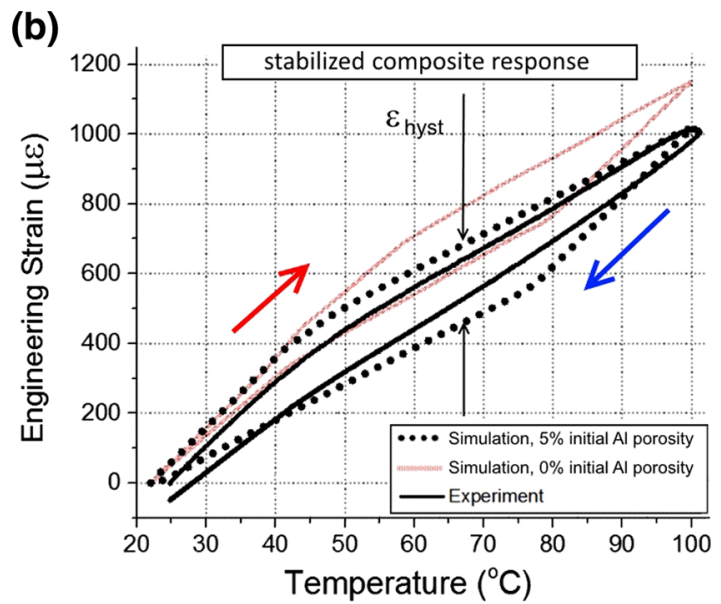

(d)

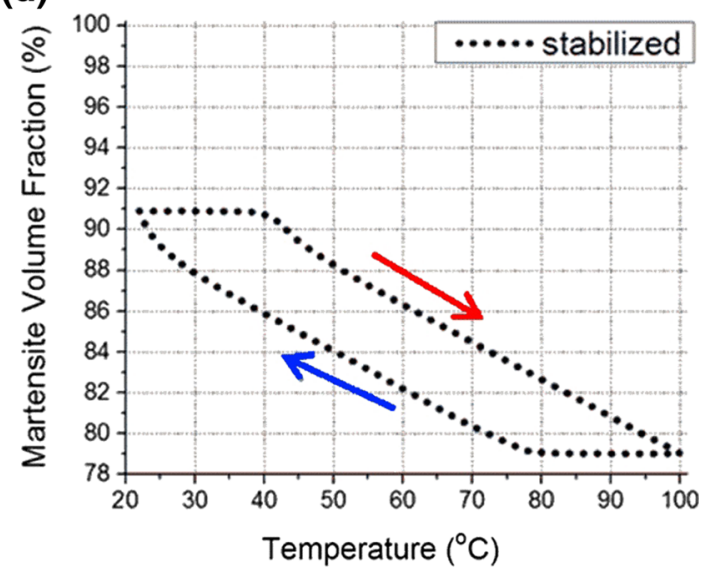

shown in Table 1 and porous plasticity for the matrix (Eq. 3 with initial porosity $5 \%$ and $q_{1}=1.5, q_{2}=5.0$, and $q_{3}=2.25$ ). Simulated evolution of martensite volume fraction in the NiTi fiber is shown for $\mathbf{c}$ the first thermal cycle and $\mathbf{d}$ subsequent thermal cycles (Color figure online)

radial function is not known, however. More importantly, a variation in the porosity distribution causes modest variation in the composite response, provided the average flow strength of the matrix is unchanged. This is rationalized in terms of the isostrain nature of deformation along the fiber axis, which tends to average the response over the matrix. A homogenous porosity is therefore adopted.

The update relation for the void volume fraction is derived from conservation of the matrix surrounding the voids

$\dot{f}=(1-f) \operatorname{tr}\left(\dot{\varepsilon}^{\mathrm{pl}}\right)$

Here, $\varepsilon^{\mathrm{pl}}$ is the plastic strain tensor. An initial porosity estimate, $f_{\text {init }}=0.05$, is adopted based on visual examination of the micrograph in Fig. 6. The matrix constitutive law was calibrated as to match the strain at the end of the 1st cycle (Fig. 12a). This furnished $q_{1}=1.5, q_{2}=5.0$, and $q_{3}=2.25$. 
(a)

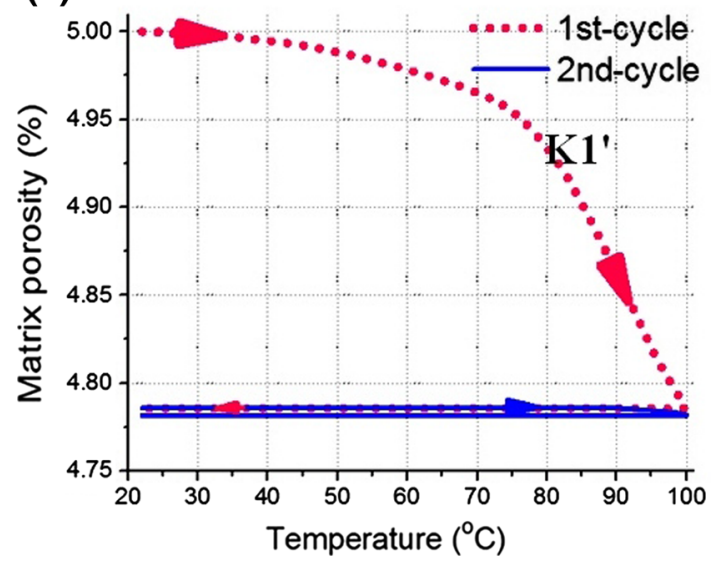

(b)

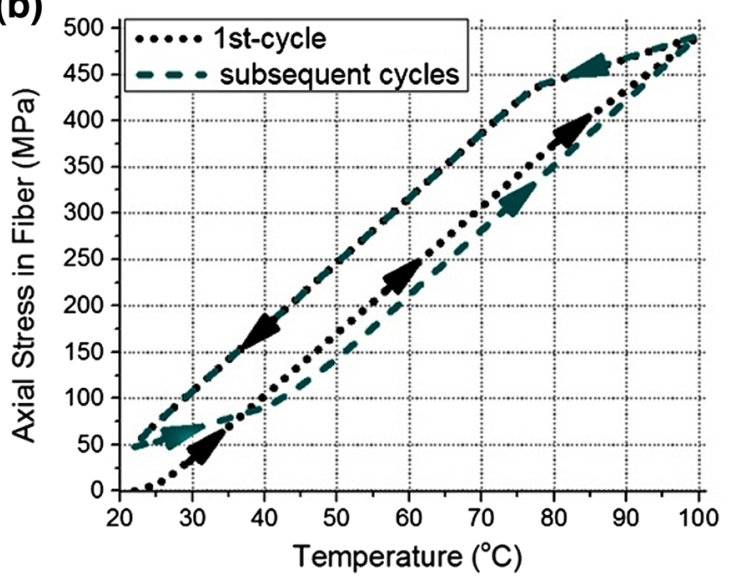

Fig. 13 Simulation results of a matrix porosity versus temperature and $\mathbf{b}$ fiber axial stress versus temperature assuming porous matrix plasticity and a reduced $f_{\text {crit }}\left(2.85 \mathrm{~J} / \mathrm{cm}^{3}\right)$ that is $1 / 2$ the pre-UAM value shown in Table 1

Figures $12 \mathrm{a}, \mathrm{b}$ show that the simulations capture the $\varepsilon-T$ response when the porous plasticity flow law with initial porosity $(=5 \%)$ and a reduced value of $f_{\text {crit }}(=1 / 2$ the preUAM value) are adopted. Specifically, the 1st-cycle $\varepsilon-T$ curve now shows two transition points $-\mathrm{K} 1$ at the onset of the $\mathrm{M} \rightarrow \mathrm{A}$ transformation in the fiber $\left(\sim 26^{\circ} \mathrm{C}\right)$, and $\mathrm{K} 1^{\prime}$ at the onset bulk yielding in the matrix $\left(\sim 80^{\circ} \mathrm{C}\right)$. The matrix yields as to contract along the fiber direction, which in turn reduces the magnitude of tension in the NiTi fiber. This change in tensile stress favors the $\mathrm{M} \rightarrow \mathrm{A}$ transformation in the NiTi fiber. This is reflected by an increase in the rate of $\mathrm{M} \rightarrow \mathrm{A}$ transformation at point $\mathrm{K} 1^{\prime}$ in Fig. 12c. For cycle 3 , the agreement between the simulation and experiments is improved significantly (Fig. 12b). Thus, porous plasticity and a reduced critical driving force $\left(f_{\text {crit }}\right)$ caused by the UAM process are key simulation features.

The reduced $f_{\text {crit }}$ is viewed as an average value for the fibers since the cyclic stress state imposed during the UAM process involves attenuation and scattering from interfaces and therefore is inhomogeneous. The reduced $f_{\text {crit }}$ essentially halves the vertical hysteresis $\left(\sigma_{\text {hyst }}\right)$ in Fig. 9a and as well as the horizontal hysteresis $\left(T_{\text {hyst }}\right)$ in Fig. 9b. $f_{\text {crit }}$ is assumed to not change during thermal cycling of the composite. This assumption is motivated by the experimental observations that fibers readily stabilize during training (Fig. 9) and that the composite response readily stabilizes during thermal cycling (Fig. 12b).

The porous plastic parameters $\left(5 \%\right.$ porosity, $q_{1}=1.5$, $q_{2}=5.0$, and $q_{3}=2.25$ in Eq. 3$)$ and $f_{\text {crit }}(=1 / 2$ the preUAM value) were obtained by a best fit of the simulations to the experimental data. In particular, the vertical hysteresis in the stabilized response (see $\varepsilon_{\text {hyst }}$, Fig. $12 \mathrm{~b}$ ) was found to be relatively insensitive to the plastic flow strength of the matrix and highly sensitive to the magnitude of $f_{\text {crit }}$. The insensitivity to flow strength is demonstrated by comparing the simulation results for elastic versus porous plastic matrices in Fig. 12b. Accordingly, $f_{\text {crit }}$ was calibrated to match the hysteresis $\left(\varepsilon_{\text {hyst }}\right)$ in the stabilized response from the experiments. The next step involved calibration of the matrix plasticity using the transient experimental results with $f_{\text {crit }}$ fixed. Figure 12 a shows that a $J_{2}$-flow law ( $0 \%$ porosity) is unable to capture the downward trend that occurs at point $\mathrm{K} 1^{\prime}$, but the porous plastic flow law does. The $5 \%$ initial porosity value and $q_{1}, q_{2}$, and $q_{3}$ values in Eq. (3) are obtained by matching the experimental magnitude of openloop strain $\varepsilon_{\mathrm{ol}}$ in Fig. 12a.

Figure 13a shows that the predicted matrix porosity decreases during the 1st thermal cycle, consistent with the reduced porosity observed in experiments after cycling (Fig. 6). A quantitative comparison is not made due to a lack of 3D cross-sectional or tomographic measurements of porosity in the experiments. The decrease in matrix porosity occurs when the fibers contract from the $\mathrm{M} \rightarrow \mathrm{A}$ transformation and put the matrix in compression. The plastic shakedown in subsequent cycles stabilizes the porosity (Fig. 13a, 2nd cycle). Figure 13b shows the simulated $\sigma-T$ phase diagram for the NiTi fibers. It is consistent with the hypothetical form in Fig. 2.

\section{Effect of NiTi Fiber Properties}

This section explores the influence of NiTi fiber properties on the composite behavior. It aims to test the robustness of the simulations, which in principle can be used to explore paths to fabricate and test the composite. An elastic matrix is assumed. The simulations are expected to capture the reduced composite CTE, based on the results in Figs. 10, 12, and Table 3. However, matrix plasticity may affect the precise positions of kink points $\mathrm{K} 1$ in the stabilized $\varepsilon-T$ response. 
Fig. 14 The influence of fiber orientation on CTE: a maximum transformation Schmid factor $\left(\mathrm{m}_{\mathrm{SF}}\right)$ for tensile loading along different crystallographic (austenitic) axes of a NiTi SMA fiber; $\mathbf{b}$ comparison of the stabilized $\varepsilon-T$ response for three fiber textures

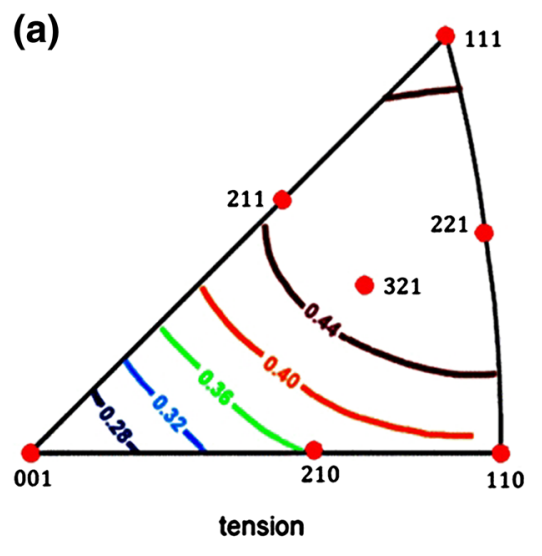

Table 4 Dependence of the composite CTE $\left(\alpha_{\text {comp }}\right.$ ) on fiber orientation, assuming a $13 \%$ fiber volume fraction. The inset shows that a smaller $m_{\mathrm{SF}}$ produces a smaller $\alpha_{\mathrm{comp}}$

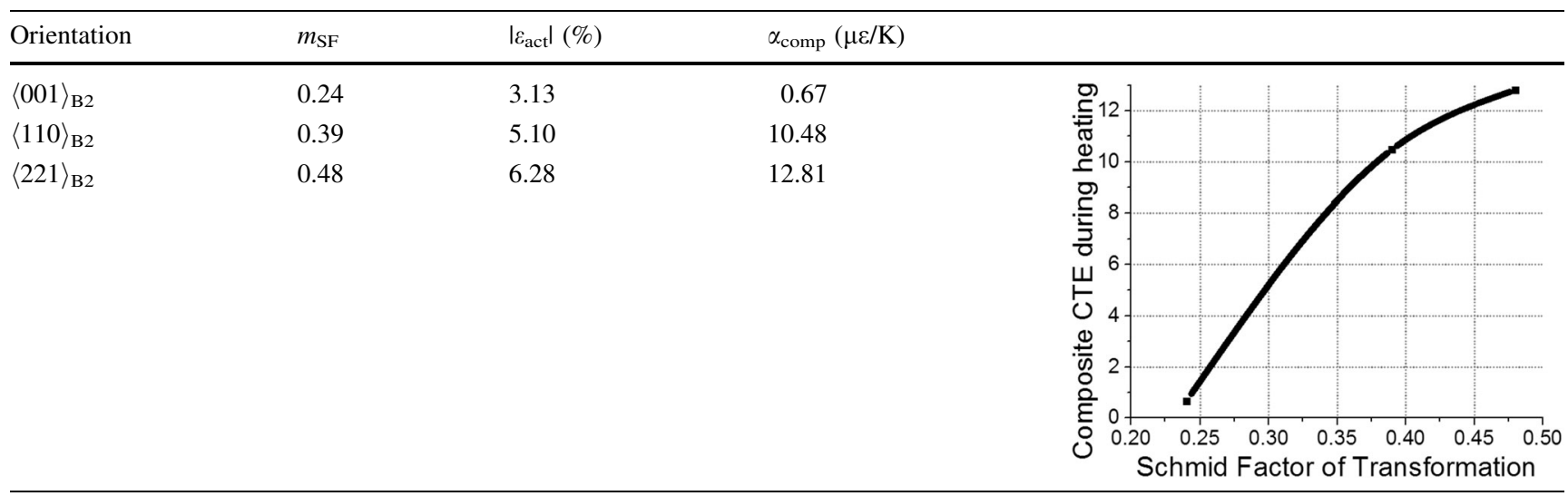

\section{Effect of NiTi Fiber Texture}

The martensitic transformation is a shear-dominated, solidstate phase transformation, and thus the formation of each martensite CVP is dependent on the local resolved shear stress $\sigma_{\text {Rss. }}$. The texture of austenite grains within NiTi fibers is an important parameter that can be varied in commercial products [49]. Figure 14a shows contours of the maximum Schmid factor $m_{\mathrm{SF}}$ as a function of the austenite (B2) crystallographic direction along the fiber axis [50]. Effectively, $m_{\mathrm{SF}}$ relates fiber response at the macroscopic scale to that at the CVP-scale in two ways: (1) $m_{\mathrm{SF}}$ is the maximum ratio of $\sigma_{\mathrm{RSS}}$ to the fiber axial stress $\sigma_{\mathrm{f}}$, when evaluated among all martensite CVPs; (2) $m_{\mathrm{SF}}$ is the maximum ratio of the magnitude of axial actuation strain $\left|\varepsilon_{\text {act }}\right|$ in the fiber to the local transformation shear $\gamma_{0}$, evaluated among all martensite CVPs. Thus, tensile loading directions for which $m_{\mathrm{SF}}$ is larger require a smaller fiber axial stress to induce the A-M transformation and they also produce a larger fiber axial actuation strain $\left|\alpha_{\text {act }}\right|$.

Three B2 fiber textures were investigated: $\langle 110\rangle_{\mathrm{B} 2}$ as used in the prior results; $\langle 221\rangle_{\mathrm{B} 2}$ for which $m_{\mathrm{SF}}$ is largest; and $\langle 001\rangle_{\mathrm{B} 2}$ for which $m_{\mathrm{SF}}$ is smallest. Figure 14b shows the predicted stabilized composite behavior for each of these fiber textures and defines the composite CTE $\left(\alpha_{\text {comp }}\right)$ and strain hysteresis $\left(\varepsilon_{\text {hyst }}\right)$. Table 4 summarizes the dependence of $m_{\mathrm{SF}}, \mid \varepsilon_{\mathrm{act}} \mathrm{t}$, and $\alpha_{\mathrm{comp}}$ on the B2 fiber texture assuming $13 \mathrm{vol} \%$ fiber fraction. A key result is that orientations with a larger $m_{\mathrm{SF}}$ do not provide a smaller $\alpha_{\text {comp. Indeed, the }}$ opposite dependence is demonstrated in the inset figure in Table 4: $\alpha_{\mathrm{comp}}$ monotonically increases with $m_{\mathrm{SF}}$ of the fiber.

The orientation dependence can be understood by developing a simple uniaxial model. During heating, the matrix ( $\mathrm{m}$ ) and fibers (f) undergo the same change in macroscopic axial strain, i.e.,

$\mathrm{d} \varepsilon_{\mathrm{f}}=\mathrm{d} \varepsilon_{\mathrm{m}}=\mathrm{d} \varepsilon_{\text {axial }}$

Force equilibrium along the axial direction requires.

$\mathrm{d} \sigma_{\mathrm{f}} v_{\mathrm{f}}+\mathrm{d} \sigma_{\mathrm{m}}\left(1-v_{\mathrm{f}}\right)=0$,

where $v_{\mathrm{f}}$ is the fiber volume fraction. For thermo-elastic deformation of the matrix,

$\mathrm{d} \varepsilon_{\mathrm{m}}=\alpha_{\mathrm{m}} \mathrm{d} T+\mathrm{d} \sigma_{\mathrm{m}} / E_{\mathrm{m}}$, 


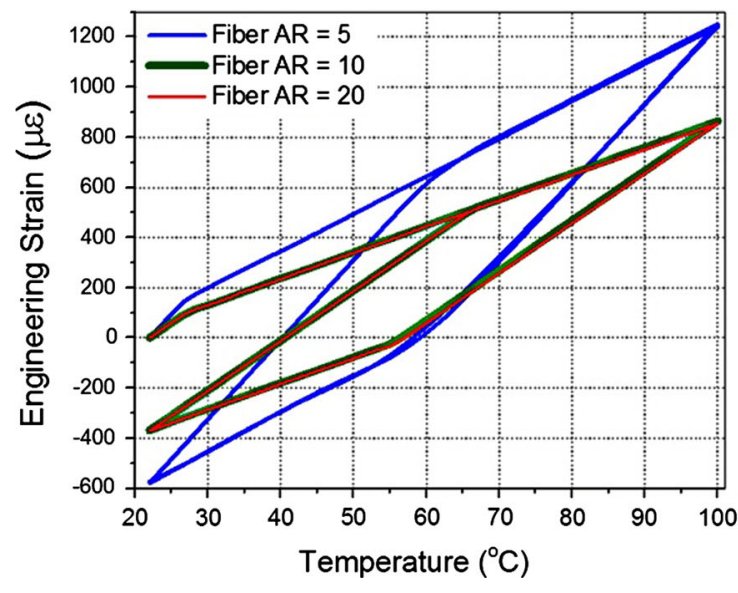

Fig. 15 (left) Simulated composite $\varepsilon-T$ curves for three different fiber aspect ratios. No significant difference is observed for $\mathrm{AR}>10$ and (right) distribution of axial stress in an $\mathrm{AR}=10$ fiber at the end

where $\alpha_{\mathrm{m}}$ is the matrix CTE and $E_{\mathrm{m}}$ is matrix Young's Modulus. Combining Eqs. (5-7),

$\mathrm{d} \varepsilon_{\text {axial }}=\alpha_{\mathrm{m}} \mathrm{d} T-\frac{\mathrm{d} \sigma_{\mathrm{f}} v_{\mathrm{f}}}{E_{\mathrm{m}}\left(1-v_{\mathrm{f}}\right)}$

Since $\sigma_{\mathrm{f}}$ is the only temperature-dependent variable on the right-hand side, $\alpha_{\text {comp }}$ can be expressed as.

$\alpha_{\text {comp }} \equiv \frac{\mathrm{d} \varepsilon_{\text {axial }}}{\mathrm{d} T}=\alpha_{\mathrm{m}}-\frac{v_{\mathrm{f}}}{E_{\mathrm{m}}\left(1-v_{\mathrm{f}}\right)} \frac{\mathrm{d} \sigma_{\mathrm{f}}}{\mathrm{d} T}$

Figures $10 \mathrm{~d}$ and $13 \mathrm{~d}$ show that the change in martensite volume fraction during transformation is small and thus the total derivative $d \sigma_{\mathrm{f}} / \mathrm{d} T$ can be approximated by the Clausius-Clapeyron slope.

$\frac{d \sigma_{\mathrm{f}}}{d T} \approx-\frac{\lambda_{\mathrm{T}}}{T \varepsilon_{\mathrm{act}}}$

The activation strain along the axis of a fully transformed fiber is.

$\varepsilon_{\mathrm{act}}=-\gamma_{0} m_{\mathrm{SF}}$

Combining Eqs. 9-11 furnishes a prediction for the composite CTE,

$\alpha_{\mathrm{comp}} \approx \alpha_{\mathrm{m}}-\frac{\lambda_{\mathrm{T}} v_{\mathrm{f}}}{T \gamma_{0} E_{\mathrm{m}}\left(1-v_{\mathrm{f}}\right)} \frac{1}{m_{\mathrm{SF}}}$

The result shows that the $\alpha_{\text {comp }}$ is minimized by minimizing $m_{\mathrm{SF}}$.

The hysteretic strain $\varepsilon_{\text {hyst }}$ can be expressed in terms of the difference in composite strain between the heating and cooling curves at some value of $T$ (see Fig. 14b). Equation 1 furnishes the difference $\Delta \sigma_{\mathrm{f}}$ in fiber stress between the $\mathrm{M} \rightarrow \mathrm{A}$ transformation on heating (for which $f_{i}=-f_{\text {crit }}$ ) and the $\mathrm{A} \rightarrow \mathrm{M}$ transformation on cooling (for which $f_{i}=f_{\text {crit }}$ ),

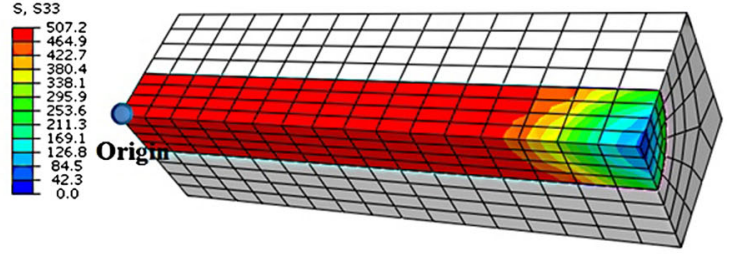

of heating, showing end effects where the axial stress is reduced over a distance $\sim$ fiber diameter

$\Delta \sigma_{\mathrm{f}}=\frac{2 f_{\text {crit }}}{\gamma_{0} m_{\mathrm{SF}}}$

Substitution into Eq. (6) gives

$\varepsilon_{\text {hyst }}=\Delta \varepsilon_{\mathrm{m}} \approx \frac{\Delta \sigma_{\mathrm{m}}}{E_{\mathrm{m}}}=-\frac{\Delta \sigma_{\mathrm{f}} v_{\mathrm{f}}}{\left(1-v_{\mathrm{f}}\right) E_{\mathrm{m}}}=\frac{2 f_{\text {crit }}}{\gamma_{0} m_{\mathrm{SF}}} \frac{v_{\mathrm{f}}}{1-v_{\mathrm{f}}} \frac{1}{E_{\mathrm{m}}}$

The result shows that decreasing $m_{\mathrm{SF}}$ increases the hysteretic strain $\varepsilon_{\text {hyst }}$.

\section{Effect of Fiber Aspect Ratio}

Figure $15 \mathrm{a}$ shows the simulated $\varepsilon-T$ response for different fiber aspect ratios (fiber length/fiber diameter) $A R=5,10$, and 20, assuming an elastic matrix and pre-UAM properties (Tables 1,2). The results show that $\alpha_{\text {comp }}$ and $\varepsilon_{\text {hyst }}$ are larger for $\mathrm{AR}=5$ compared to $\mathrm{AR}=10$ or 20 . This arises from fiber ends where the axial stress in the fiber is reduced as shown in Fig. 15b. Here, the fiber and matrix do not satisfy isostrain conditions of Eq. (5). From St. Venant's Principle, these regions extend a distance-fiber diameter. Based on the theory of fiber-reinforced composites, even greater distances are expected if the matrix and interface yield or slide (e.g., see [51]).

\section{Conclusions}

This paper reports on the fabrication and experimental characterization of UAM-fabricated Al matrix composites with $\sim 13 \mathrm{vol} \%$ aligned NiTi shape memory alloy wires with a $\langle 110\rangle_{\mathrm{B} 2}$ crystallographic texture. The results show 
that upon heating, the composite CTE decreases from $\sim 20 \times 10^{-6} / \mathrm{K}$ at $T<40{ }^{\circ} \mathrm{C}$ to $\sim 11 \times 10^{-6} / \mathrm{K}$ from 40 to $100{ }^{\circ} \mathrm{C}$. The reduced CTE at higher $T$ is attributed to a martensite-to-austenite phase transformation in the NiTi SMA wires that imparts an axial contraction of the wires, thereby opposing thermal expansion. A microstructural finite element model is able to closely reproduce the experimental composite $\varepsilon$ versus $T$ response-both in the transient 1 st cycle and stabilized subsequent cycles. However, a successful agreement is achieved only if porous matrix plasticity is incorporated and if the UAM process is assumed to reduce the critical thermodynamic driving force $\left(f_{\text {crit }}\right)$ for the forward and backward phase transformation. The latter suggests that UAM may impart changes that reduce hysteresis in the SMA response of the fibers. The simulations predict that fibers with $\langle 100\rangle_{\mathrm{B} 2}$ texture can reduce the composite CTE to $\sim 4 \times 10^{-6} / \mathrm{K}$ on average over the range $25^{\circ} \mathrm{C}<T<100{ }^{\circ} \mathrm{C}$, and that fiber aspect ratios (length:diameter) $>10$ are needed to achieve high fiber efficiency and a reduced composite CTE.

Overall, the results demonstrate the viability of fabricating lightweight, reduced CTE composites via ultrasonic additive manufacturing. Some key performance issues include the potential for structural fatigue, whereby cracks may nucleate and lead to component failure [52] and also functional fatigue, whereby cyclic strain may accumulate under a sustained macroscopic stress from a variety of mechanisms in the martensite phase [53] as well as plasticity in the austenite phase [54-57], particularly at elevated temperature [58]. For Al matrix composites, such cyclic straining can arise from a mismatch in coefficients of thermal expansion, even in the absence of any phase transformations [59]. Understanding these phenomena may require an extension of the simulations to include potential interfacial sliding, more accurate distributions of matrix porosity, and plastic deformation in NiTi wires. The last phenomenon can stem from stress concentrations at the intergranular, grain-neighborhood scale [42] and also at the scale of individual martensite variants $[60,61]$. The latter is at the $\mathrm{nm}$ scale and therefore beyond the scope of the present approach. However, the other phenomena can be incorporated explicitly into refined versions of the simulations.

Acknowledgments The authors are grateful to Alan Pelton (G. Rau, Inc.) for discussions on the texture of NiTi fibers used in this study. $\mathrm{XC}$ and PA acknowledge support of the DOE Office of Basic Energy Sciences (Grant SC-0001258) and the Ohio Supercomputer Center (Grant PAS0676). AH and MD acknowledge support of the NSF I/UCRC on Smart Vehicle Concepts at The Ohio State University (http://www.SmartVehicleCenter.org). AH was also supported by a NSF Graduate Fellowship (Grant 1102690). Any opinions, findings, and conclusions or recommendations expressed in this material are those of the authors and do not necessarily reflect the views of the National Science Foundation. The technical assistance of Phillip Evans (MIT Lincoln Laboratory), Walter Green (OSU), Steven Bright
(OSU), and discussions with Richard Boger (Dassault Systèmes Simulia Corp.) are gratefully acknowledged.

\section{References}

1. Thorat RR, Risanti DD, San Martín D, Garces G, del Castillo PRD, van der Zwaag S (2009) On the transformation behaviour of NiTi particulate reinforced AA2124 composites. J Alloys Compd 477(1):307-315

2. Ni DR, Wang JJ, Zhou ZN, Ma ZY (2014) Fabrication and mechanical properties of bulk $\mathrm{NiTi}_{\mathrm{p}} / \mathrm{Al}$ composites prepared by friction stir processing. J. Alloys Compd 586:368-374

3. Smith RC (2005). Smart material systems: model development. Society for Industrial and Applied Mathematics (Philadephia, PA)

4. Jani J, Leary M, Subic A, Gibson M (2014) A review of shape memory alloy research, applications, and opportunities. Mater Des 56:1078-1113

5. Jonnalagadda KD, Sottos NR, Qidwai MA, Lagoudas DC (1998) Transformation of embedded shape memory alloy ribbons. J Intell Mater Syst Struct 9:379-390

6. Bollas D, Pappas P, Parthenios J, Galiotis C (2007) Stress generation by shape memory alloy wires embedded in polymer composites. Acta Mater 55:5489-5499

7. Furuya Y, Sasaki A, Taya M (1993) Enhanced mechanical properties of TiNi shape memory fiber/Al matrix composite. Mater Trans JIM 34(3):224-227

8. Armstrong WD, Kino H (1995) Martensitic transformations in a NiTi fiber reinforced 6061 aluminum matrix composite. J Intell Mater Syst Struct 6(6):809

9. Mizuuchi K (2000) The fabrication and thermomechanical behavior of Al and Ti SMA composites. J Met 52(10):26-31

10. Kong CY, Soar RC, Dickens PM (2004) Ultrasonic consolidation for embedding SMA fibres within aluminium matrices. Compos Struct 66:421-427

11. Hahnlen R, Dapino M (2012) Stress-induced tuning of ultrasonic additive manufacturing Al-NiTi composites. SPIE Smart Structures/NDE, San Diego

12. Hahnlen R, Dapino MJ (2014) NiTi-Al interface strength in ultrasonic additive manufacturing composites. Composites Part B 59:101-108

13. Graff K (2011) Ultrasonic additive manufacturing. ASM handbooks: welding fund and processes. ASM International, Materials Park

14. Sriraman M, Gonser M, Fujii H, Babu S, Bloss M (2011) Thermal transients during processing of materials by very high power ultrasonic additive manufacturing. J Mater Process Technol 211:1650-1657

15. Dehoff RR, Babu SS (2010) Characterization of interfacial microstructures in 3003 aluminum alloy blocks fabricated by ultrasonic additive manufacturing. Acta Mater 58(13):4305-4315

16. Friel RJ, Harris RA (2010) A nanometre-scale fibre-to-matrix interface characterization of an ultrasonically consolidated metal matrix composite. Proc Inst Mech Eng Part L 224(1):31-40

17. Hahnlen RM (2012) Characterization and modeling of active metal-matrix composites with embedded shape memory alloys (PhD Dissertation). The Ohio State University

18. Li JF, Zheng ZQ, Li XW, Peng ZW (2009) Application of shape memory alloy TiNi in low thermal expansion copper composites. Mater Des 30(2):314-318

19. Hu J, Zhang Q, Liu Y, Wu G (2014) Phase transformation behaviors of TiNi fibers embedded in an aluminum matrix. J Alloys Compd 589:491-497

20. Auricchio F, Petrini L (2004) A three-dimensional model describing stress-temperature induced solid phase 
transformations: thermomechanical coupling and hybrid composite applications. Int J Num Methods Eng 61(5):716-737

21. Freed Y, Aboudi J (2009) Thermomechanically coupled micromechanical analysis of shape memory alloy composites undergoing transformation induced plasticity. J Intell Mater Syst Struct 20(1):23-28

22. Zhu Y, Dui G (2009) Effect of fiber shape on mechanical behavior of composite with elastoplastic matrix and SMA reinforcement. J Mech Behav Biomed Mater 2(5):454-459

23. Chatzigeorgiou G, Chemisky Y, Meraghni F (2015) Computational micro to macro transitions for shape memory alloy composites using periodic homogenization. Smart Mater Struct 24(3):035009

24. Damanpack AR, Aghdam MM, Shakeri M (2015) Micro-mechanics of composite with SMA fibers embedded in metallic/polymeric matrix under off-axial loadings. Eur J Mech A 49:467-480

25. Chen X, Nguyen TD (2011) Influence of thermoviscoelastic properties and loading conditions on the recovery performance of shape memory polymers. Mech Mater 43:127-138

26. Hehr A, Chen X, Pritchard J, Dapino MJ, Anderson PM (2015) Al-NiTi metal matrix composites for zero CTE materials: fabrication, design, and modeling. In: Sano T, Srivatsan TS (eds) Advanced composites for aerospace, marine, and land applications II. Wiley, Hoboken

27. Kumar P, Lagoudas D (2008) Introduction to shape memory alloys. In: Lagoudas DC (ed) Shape memory alloys: modeling and engineering applications. Springer, New York, pp 1-50

28. ASTM Standard F2516-14 (2014) Standard test method for tension testing of nickel-titanium superelastic materials. ASTM International, West Conshohocken

29. ASTM Standard F2004-05 (2010) Standard test method for transformation temperature of nickel-titanium alloys by thermal analysis. ASTM International, West Conshohocken

30. Wolcott P, Hehr A, Dapino MJ (2014) Optimized welding parameters of $\mathrm{Al} 6061$ ultrasonic additive manufactured structures. J Mater Res 29:2055-2206

31. Vishay (2010) Vishay micro measurements (Malvern, PA) http:// www.vishay.com

32. Voort GF (2004) ASM handbook: metallography and microstructures, vol 9. ASM International, Materials Park

33. Hehr A, Dapino M (2015) Interfacial shear strength estimates of NiTi-Al matrix composites fabricated via ultrasonic additive manufacturing. Composites Part B 77:199-208

34. Foster DR, Dapino MJ, Babu SS (2013) Elastic constants of ultrasonic additive manufactured Al 3003-H18. Ultrasonics 53(1):211-218

35. ASTM E8/E8M-15a (2015) Standard test methods for tension testing of metallic materials. ASTM International, West Conshohocken

36. ASTM Standard E21-09 (2009) Standard test methods for elevated temperature tension tests of metallic materials. ASTM International, West Conshohocken

37. Manchiraju S, Anderson PM (2010) Coupling between martensitic phase transformations and plasticity: a microstructure-based finite element model. Int J Plast 26:1508-1526

38. Abaqus (2012) 6.12 Documentation. Dassault Systèmes Simulia Corporation (Waltham, MA). http://www.3ds.com

39. Chen X (2015) From nano-precipitates to macroscale composites: How inclusion-matrix interactions influence the behaviors of shape memory alloys and structures. Ph.D. Dissertation, The Ohio State University

40. Otsuka K, Ren X (2005) Physical metallurgy of Ti-Ni-based shape memory alloys. Prog Mater Sci 50:511-678

41. Thamburaja P, Anand L (2001) Polycrystalline shape-memory materials: effect of crystallographic texture. J Mech Phys Solids 49:709-737
42. Paranjape H, Anderson PM (2014) Texture and grain neighborhood effects on Ni-Ti shape memory alloy performance. Modell Simul Mater Sci Eng 22:075002

43. Kim K, Daly S (2013) The effect of texture on stress-induced martensite formation in nickel-titanium. Smart Mater Struct 22:075012

44. Liu Y, Favier D, Orgeas L (2006) Hysteretic behavior of ferroelasticity of NiTi in shear. J Intell Mater Syst Struct 17:1121-1126

45. Van Humbeeck J (2003) Damping capacity of thermoelastic martensite in shape memory alloys. J Alloys Compd 355:58-64

46. Blanter MS, Golovin IS, Neuhäuser H, Sinning H-R (2007) Internal friction at phase transformations. In: Hull R, Osgood RM, Parisi J, Warlimont $\mathrm{H}$ (eds) Internal friction in metallic materials: a handbook. Springer, Berlin, pp 121-128

47. Gurson A (1977) Continuum theory of ductile rupture by void nucleation and growth: Part I-Yield criteria and flow rules for porous ductile media. J Eng Mater Technol 99:2-15

48. Tvergaard V (1981) Influence of voids on shear band instabilities under plane strain conditions. Int J Fract 17:389-407

49. Robertson SW, Gong XY, Ritchie RO (2006) Effect of product form and heat treatment on the crystallographic texture of austenitic nitinol. J Mater Sci 41(3):621-630

50. Ball JM, James RD (1987) Fine phase mixtures as minimizers of energy. Arch Rat Mech Anal 100:13-52

51. Chawla KK (2012) Micromechanics of composites. Composite materials: science and engineering. Springer, New York, pp 337-385

52. Eggeler G, Hornbogen E, Yawny A, Heckmann A, Wagner M (2004) Structural and functional fatigue of NiTi shape memory alloys. Mater Sci Eng, A 378:24-33

53. Stebner AP, Vogel SC, Noebe RD, Sisneros TA, Clausen B, Brown DW, Garg A, Brinson LC (2013) Micromechanical quantification of elastic, twinning, and slip strain partitioning exhibited by polycrystalline, monoclinic nickel-titanium during large uniaxial deformations measured via in-situ neutron diffraction. J Mech Phys Solids 61:2302-2330

54. Liu Y, Xie Z, Van Humbeeck J (1999) Cyclic deformation of NiTi shape memory alloys. Mater Sci Eng A 273-275:673-678

55. Kockar B, Karaman I, Kim JI, Chumlyakov YI, Sharp J, Yu C-J (2008) Thermomechanical cyclic response of an ultrafine-grained NiTi shape memory alloy. Acta Mater 56:3630-3646

56. Ye J, Mishra RK, Pelton AR, Minor AM (2010) Direct observation of the NiTi martensitic phase transformation in nanoscale volumes. Acta Mater 58:490-498

57. Pfetzing-Micklich J, Ghisleni R, Simon T, Somsen C, Michler J, Eggeler G (2012) Orientation dependence of stress-induced phase transformation and dislocation plasticity in NiTi shape memory alloys on the micro scale. Mater Sci Eng A 538:265-271

58. Benafan O, Noebe RD, Padula SA II, Garg A, Clausen B, Vogel S, Vaidyanathan R (2013) Temperature dependent deformation of the B2 austenite phase of a NiTi shape memory alloy. Int J Plast 51:103-121

59. Zhang HY, Anderson PM, Daehn GS (1994) Analysis of thermally-induced stress and strain in continuous fiber-reinforced composites. Metall Mater Trans A 25:415-425

60. Bowers ML, Chen X, De Graef M, Anderson PM, Mills MJ (2014) Characterization and modeling of defects generated in pseudoelastically deformed NiTi microcrystals. Scr Mater 78:69-72

61. Norfleet DM, Sarosi PM, Manchiraju S, Wagner MF-X, Uchic MD, Anderson PM, Mills MJ (2009) Transformation-induced plasticity during pseudoelastic deformation in Ni-Ti microcrystals. Acta Mater 57:3549-3561 